\title{
Estudos pré-clínicos e clínicos de espécies vegetais selecionadas de países pertencentes ao Mercosul e aspectos toxicológicos
}

\section{Preclinical and clinical studies of selected plant species in Mercosul countries and toxicological aspects}

Recebido em: 24/02/2017

Aceito em: 03/08/2017
Camile Cecconi CECHINEL-ZANCHETT

Programa de Pós-graduação em Ciências Farmacêuticas, Universidade do Vale do Itajai -UNIVALI. Rua Uruguai, 458, CEP 88302-202. Itajaí, SC, Brasil. E-mail:

camilecechinel@gmail.com

\begin{abstract}
Medicinal plants are used to prevent and treat diseases and have been used by about $80 \%$ of the population for primary health care. The rich biodiversity of Brazil and neighboring Countries offers a unique and unparalleled potential for the discovery and development of bioactive agents. This study aimed to do a review of preclinical and clinical studies of herbal and plant species selected from Mercosul countries, and toxicological aspects. Based on previous work, the species with the highesAt number of register in Brazil (Anvisa), Aesculus hippocastanum (Horse Chestnut) and Mikania glomerata (Guaco); the most used as simple herbal medicines in Argentina Cynara scolymus L. (Artichoke) and Solanum dulcamara (Dulcamara); the sold medicinal plants in Paraguay Peumus boldus Mol. (Bilberry), and Borago officinalis (Borage); the most consumed in northern Uruguay Aloe vera (Aloe) and Passiflora edulis (Passion flower) and from Venezuela, Hedera helix (Hera) were selected for a review about pharmacology studies. Surveys on pre-clinical and clinical trials of these species were conducted on Google Scholar, PubMed and Science Direct databases in April 2016, in Portuguese and English. Then the most relevant articles were selected, using animals (rats, rabbits or mice), cellular or bacterial strains or clinical trials. About preclinical and clinical studies, Aloe and Artichoke showed the most substantial number of publications.
\end{abstract}

Keywords: phytotherapy; Mercosul; medicinal plants

\section{RESUMO}

As plantas medicinais são utilizadas para a prevenção e tratamento de doenças, sendo usada por cerca de $80 \%$ da população para o cuidado primário à saúde. A rica biodiversidade do Brasil e países vizinhos oferece um potencial único e incomparável para a descoberta e desenvolvimento de agentes bioativos. O objetivo desse trabalho foi fazer uma revisão sobre estudos pré-clínicos e clínicos de espécies vegetais selecionadas dos países do Mercosul e aspectos toxicológicos. Com base em trabalho publicado anteriormente pelo autor, foram selecionadas as espécies com maior número de registro na Anvisa no Brasil (Aesculus hippocastanum - Castanha da Índia e Mikania glomerata- Guaco); as mais utilizadas como medicamentos fitoterápicos simples na Argentina (Cynara scolymus L. - Alcachofra e Solanum dulcamara - Dulcamara); as plantas medicinais mais vendidas no Paraguai (Peumus boldus Mol. - Boldo e Borago officinalis - Borragem); as mais consumidas no norte do Uruguai (Aloe vera - Aloe e Passiflora edulis - Maracujá) e da Venezuela a Hedera helix (Hera) por ser muito popular no país seu consumo. Foram realizadas pesquisas nas bases de dados Google Acadêmico, PubMed e Science Direct no mês de abril de 2016, sobre ensaios pré-clínicos e clínicos dessas espécies vegetais, em português e inglês, sendo selecionados os artigos mais relevantes, com uso de animais (ratos, coelhos ou camundongos), linhagens celulares ou bacterianas, ou estudos clínicos. Em relação aos estudos pré-clínicos e clínicos, Aloe e Alcachofra, foram as que apresentaram maior número de publicações.

Palavras-chave: fitoterapia; mercosul; plantas medicinais 
INTRODUÇÃO

Desde a antiguidade, o homem tem se esforçado para estudar e analisar os produtos naturais do mundo ao seu redor, e até o século $\mathrm{XX}$, as plantas eram a maior fonte terapêutica que existia (1). Existem cerca de 100 milhões de diferentes espécies no mundo, que desempenham funções primordiais para manter a estabilidade dos ecossistemas criando, juntas, as bases para a nossa sobrevivência, como alimentos, água e oxigênio, além de medicamentos, combustíveis e clima estável (2). Destaca-se que o Brasil abriga a maior biodiversidade do mundo, com mais de $20 \%$ do número total de espécies da Terra, tornando-o o principal país entre os 17 com maior biodiversidade (2).

A diversidade biológica imensamente rica do Brasil e países vizinhos oferecem um potencial único e incomparável como possíveis fontes de novos indícios para o desenvolvimento de fármacos e outros preciosos agentes bioativos (3). Bolzani e cols. (2014) afirmaram que, dentro da biodiversidade, há uma grande variedade de substâncias naturais com estruturas peculiares, sendo uma das maiores fontes de moléculas com potencial para a química medicinal e desenvolvimento de novos fármacos (4).

Estima-se que, no Brasil, apenas cerca de $5-10 \%$ das plantas existentes foram, ou estão sendo, estudadas cientificamente, com o intuito de comprovar sua eficácia terapêutica (5). A fitoterapia é o recurso de prevenção e tratamento de doenças com plantas medicinais, sendo a forma mais antiga e fundamental de medicina no mundo. As plantas contêm princípios ativos capazes de curar diversas morbidades, e a partir destas propriedades terapêuticas se deu o surgimento da medicina alopática moderna (6).

As plantas contêm importantes compostos bioativos e comumente têm promissora atividade biológica, podendo controlar diversas doenças bacterianas e fúngicas. A maioria dos extratos de plantas e frutos representa uma rica fonte de agentes antioxidantes, anti-inflamatórios, anticancer, antifúngicos e antibacterianos (7-9). Cerca de $80 \%$ da população confiam na medicina tradicional para o cuidado primário à saúde, sendo essa a base de plantas. Os produtos derivados de plantas medicinais também exercem importante papel nos sistemas de saúde nos $20 \%$ restantes da população em países desenvolvidos (3).

Dessa forma, o objetivo desse trabalho foi realizar uma revisão de espécies vegetais selecionadas dos países Brasil, Argentina, Paraguai, Uruguai e Venezuela quanto aos aspectos relacionados à toxicologia.

\section{MÉTODOS}

Em publicação prévia (10), foi realizada uma revisão de literatura sobre estudos e legislações relacionadas a fitoterápicos nos países do Mercosul, e de acordo com o encontrado em sites oficinais e artigos, foram selecionadas nove espécies da seguinte forma: do Brasil as duas espécies com maior número de registro de medicamentos fitoterápicos na Anvisa, Aesculus hippocastanum (Castanha da Índia) e Mikania glomerata (Guaco). Da Argentina, as espécies mais utilizadas como medicamentos fitoterápicos simples, Cynara scolymus L. (Alcachofra) e Solanum dulcamara (Dulcamara). Do Paraguai, as plantas medicinais mais vendidas, Peumus boldus Mol. (Boldo) e Borago officinalis (Borragem). Do Uruguai, foram escolhidas a Aloe vera (Aloe) e Passiflora edulis (Maracujá) por serem indicadas como as mais consumidas por hortas familiares no norte do Uruguai, e da Venezuela, foi escolhida Hedera helix (Hera) por ser muito popular no país seu consumo.

Foram então realizadas pesquisas nas bases de dados Google Acadêmico, PubMed e Science Direct, no mês de abril de 2016, sobre ensaios pré-clínicos e clínicos dessas espécies vegetais, em português e inglês, dos últimos 10 anos para Aesculus hippocastanum (Castanha da Índia) e Mikania glomerata (Guaco) por possuírem menor quantidade de estudos, e dos últimos 5 anos para as demais que são mais estudadas, sendo selecionados artigos com uso de animais (ratos, coelhos ou camundongos), linhagens celulares ou bacterianas, ou estudos clínicos.

Os critérios de exclusão foram estudos com misturas ou formulações contendo mais de uma espécie e estudos pré-clínicos com uso de células vegetais ou insetos. As palavras chaves selecionadas foram "Aesculus hippocastanum", "horse chestnut", "castanha da Índia", "Aesculus hippocastanum in vivo", "Mikania glomerata", "Cynara scolymos", "Solanum dulcamara L.", "bittersweet solanum", "Peumus boldus Mol.", "boldo", "Borago officinalis", "borragem" e "Hedera helix".

Os dados obtidos foram inseridos em tabelas ou gráficos, utilizando como base o programa Microsoft Excel 2003 versão para Windows, e foram posteriormente analisados.

\section{RESULTADOS E DISCUSSÃO}

Estudos pré-clínicos e clínicos das principais espécies vegetais selecionadas. As plantas medicinais 
estão ganhando cada vez maior aceitação, pois muitos estudos têm confirmado sua eficácia, porém seu uso deve ser cuidadoso e responsável (11). Nos Quadros 1 e 2 estão os estudos pré-clínicos e clínicos encontrados na literatura dos últimos 10 anos, sobre as duas espécies com maior número de registros no Brasil, na Anvisa, Aesculus hippocastanum (Castanha da Índia) e Mikania glomerata (Guaco).

Aesculus hippocastanum L (Quadro 1), conhecida popularmente como castanha da Índia, é uma espécie nativa da Europa, mas distribuída globalmente. Na medicina, as sementes e casca de ramos jovens são utilizadas, sendo o extrato da semente amplamente divulgado como medicamento fitoterápico, recomendado para o tratamento de insuficiência venosa crônica, edema traumático, hemorroidas ou edema pós-operatório (12).

Os estudos encontrados são principalmente sobre o efeito antioxidante, anti-inflamatório e hepatoprotetor. As sementes são utilizadas para tratamento de proble- mas vasculares e inflamatórios. Na medicina tradicional da Turquia, o chá preparado das sementes era usado para o tratamento de pedras nos rins e dores estomacais, enquanto uma fração da semente era engolida para melhorar os sintomas de hemorroidas (13).

As sementes são inodoras, com pouco odor quando partidas e a casca possui sabor adstringente. Para ser utilizada com fins terapêuticos, devem estar secas e maduras. A maior parte do efeito terapêutico dessa planta é devida à aescina, principal constituinte químico da espécie (12). A $\beta$-aescina é o principal constituinte, presente nas sementes, que pode ser detectada através da verificação da presença de saponinas triterpênicas (14).

O "guaco" (Quadro 2), é nativa do sul do Brasil, pertencente ao gênero Mikania, da família Asteraceae, subfamília Asteroideoe. Possui propriedades terapêuticas como broncodilatador, antialérgico e antiasmático. Também é anti-hemorrágico, antiviral e antimicrobiano (15).

Quadro 1. Estudos pré-clínicos e clínicos de Aesculus hippocastanum (2006-2016)

\begin{tabular}{|c|c|c|c|c|}
\hline Autor (ano) & Origem & Objetivo & Tipo de estudo & Atividade biológica encontrada \\
\hline \multicolumn{5}{|c|}{ Aesculus hippocastanum (Castanha da Índia) } \\
\hline $\begin{array}{l}\text { Küçükkurt e cols. } \\
\text { (13) }\end{array}$ & Turquia & $\begin{array}{l}\text { Avaliação do efeito do extrato etanó- } \\
\text { lico das sementes in vivo }\end{array}$ & $\begin{array}{l}\text { Pré-clínico: Camundongos } \\
\text { machos }\end{array}$ & $\begin{array}{l}\text { Atividade antioxidante e hepatopro- } \\
\text { tetora }\end{array}$ \\
\hline Jiang e cols. (64) & China & $\begin{array}{l}\text { Avaliação do efeito da aescina em } \\
\text { camundongos induzidos à lesão hepá- } \\
\text { tica aguda por endotoxina }\end{array}$ & $\begin{array}{l}\text { Pré-clínico: Camundongos } \\
\text { Swiss machos }\end{array}$ & $\begin{array}{l}\text { Efeito antioxidante, anti-inflamatório } \\
\text { e protetor sobre a lesão hepática }\end{array}$ \\
\hline Avci e cols. (65) & Turquia & $\begin{array}{l}\text { Avaliação do efeito da aescina nos } \\
\text { parâmetros bioquímicos de camun- } \\
\text { dongos com dieta hiperlipídica }\end{array}$ & Pré-clínico: Camundongos & $\begin{array}{l}\text { Redução de leptina e aumento no } \\
\text { HDL-colesterol. Não teve efeito no } \\
\text { LDL-colesterol. }\end{array}$ \\
\hline Xin e cols. (66) & China & $\begin{array}{l}\text { Investigação da escina sobre efeitos } \\
\text { anti-inflamatórios sinérgicos quando } \\
\text { combinada com glicocorticóides }\end{array}$ & $\begin{array}{l}\text { Pré-clínico: } \\
\text { Ratos e linha celular de } \\
\text { monócitos -macrófagos } \\
\text { RAW264.7 }\end{array}$ & $\begin{array}{l}\text { A escina e glucocorticóide têm efeito } \\
\text { anti - inflamatório sinérgico. Regula- } \\
\text { ção de negativa de óxico nítrico (N0), } \\
\text { fator de necrose tumoral- } \alpha \text { (TNF- } \alpha \text { ) e } \\
\text { interleucina-1 } \beta \text { (IL- } 1 \beta) \text {. }\end{array}$ \\
\hline Kimura e cols. (67) & Japão & $\begin{array}{l}\text { Avaliação in vivo da eficácia de } \\
\text { proantocianidinas na glicemia e } \\
\text { efeitos anti-obesidade a longo prazo } \\
\text { em ratos obesos }\end{array}$ & $\begin{array}{l}\text { Pré-clínico: } \\
\text { Camundongos fêmeas }\end{array}$ & $\begin{array}{l}\text { Supressão da elevação da glicemia por } \\
\text { amido. Efeito anti-obesidade a partir } \\
\text { da } 9^{a} \text { semana (ganho de peso, tecido } \\
\text { adiposo, concentrações de colesterol } \\
\text { e leptina e normalização de esteatose } \\
\text { hepática). }\end{array}$ \\
\hline Felipe e cols. (12) & Brasil & $\begin{array}{l}\text { Avaliação in vitro de citotoxicidade, } \\
\text { genotoxicidade, mutagenicidade e } \\
\text { atividade antioxidante }\end{array}$ & $\begin{array}{l}\text { Pré-clínico: } \\
\text { Bactérias }\end{array}$ & $\begin{array}{l}\text { Atividade antioxidante, genotóxica e } \\
\text { mutagênica }\end{array}$ \\
\hline
\end{tabular}


Quadro 2. Estudos pré-clínicos e clínicos de Mikania glomerata (2006-2016)

\begin{tabular}{|c|c|c|c|c|}
\hline Autor (ano) & Origem & Objetivo & Tipo de estudo & Atividade biológica encontrada \\
\hline \multicolumn{5}{|c|}{ Mikania glomerata (Guaco) } \\
\hline Fulanetti e cols. (11) & Brasil & $\begin{array}{l}\text { Avaliação da toxicidade em ra- } \\
\text { tas gestantes hipertensas }\end{array}$ & $\begin{array}{l}\text { Pré-clínico: Ratas Wistar } \\
\text { gestantes }\end{array}$ & $\begin{array}{l}\text { Não foi observada teratogenicidade, } \\
\text { nem controle sobre o efeito vasocons- } \\
\text { tritor. }\end{array}$ \\
\hline Mourão e cols. (68) & Brasil & $\begin{array}{l}\text { Avaliação do efeito do extrato } \\
\text { hidroalcoolico sobre a ativida- } \\
\text { de do veneno da cobra Bothrops } \\
\text { jararaca }\end{array}$ & $\begin{array}{l}\text { Pré-clínico: Ratos Wistar } \\
\text { machos }\end{array}$ & $\begin{array}{l}\text { Efeito anti-inflamatório e anti-hemor- } \\
\text { rágico }\end{array}$ \\
\hline Santana e cols. (15) & Brasil & $\begin{array}{l}\text { Mecanismo de sedação e efeito } \\
\text { ansiolítico }\end{array}$ & $\begin{array}{l}\text { Pré-clínico: Camundongos } \\
\text { machos adultos Swiss }\end{array}$ & $\begin{array}{l}\text { Efeito ansiolítico mediado por ácido } \\
\text { gama-aminobutírico (GABA), e aumento } \\
\text { de GABA e redução das concentrações de } \\
\text { glutamate e aspastato no hipocampo. }\end{array}$ \\
\hline Barbosa e cols. (69) & Brasil & $\begin{array}{l}\text { Avaliação do efeito preventi- } \\
\text { vo do extrato hidroalcoolico } \\
\text { contra quimioterápico e efeito } \\
\text { antioxidante }\end{array}$ & $\begin{array}{l}\text { Pré-clínico: Camundongos } \\
\text { machos Swiss }\end{array}$ & $\begin{array}{l}\text { Nenhum dado genotóxico, mas apresen- } \\
\text { tou interação medicamentosa }\end{array}$ \\
\hline Floriano e cols. (70) & Brasil & $\begin{array}{l}\text { Parâmetros clínicos e laborato- } \\
\text { riais em animais envenenados } \\
\text { por veneno de cascavel }\end{array}$ & Pré-clínico: Ratos Wistar & Recuperação mais rápida da sedação \\
\hline Freitas e cols. (71) & Brasil & $\begin{array}{l}\text { Avaliação do pré-tratamento } \\
\text { em parâmetros inflamatórios e } \\
\text { estresse oxidativo no pulmão }\end{array}$ & $\begin{array}{l}\text { Pré-clínico: Ratos Wistar } \\
\text { machos }\end{array}$ & $\begin{array}{l}\text { Efeito protetor do dano oxidativo pul- } \\
\text { monar e redução da infiltração inflama- } \\
\text { tória no pulmão }\end{array}$ \\
\hline Costa e cols. (72) & Brasil & $\begin{array}{l}\text { Avaliação da capacidade de } \\
\text { induzir danos no ácido deso- } \\
\text { xirribonucleico (DNA) e efeitos } \\
\text { mutagênicos da infusão e ma- } \\
\text { ceração }\end{array}$ & $\begin{array}{l}\text { Pré-clínico: In vitro com } \\
\text { células HTC }\end{array}$ & $\begin{array}{l}\text { Nas maiores doses, apresentaram geno- } \\
\text { toxicidade e alterações no DNA }\end{array}$ \\
\hline
\end{tabular}

Por ser uma planta nativa do Brasil, os estudos encontrados na literatura são todos brasileiros. Pode ser observado que mesmo sendo conhecido por seus efeitos no trato respiratório, as pesquisas encontradas também abordam toxicidade, efeito ansiolítico, anti-hemorrágico e antioxidante.

O xarope de Guaco é um dos produtos mais utilizados para tratar sintomas de bronquite asmática, gripe e rouquidão. A cápsula de extrato seco de Guaco é utilizada na saúde primária e é recomendada pelo Programa Brasileiro de Plantas Medicinais e Fitoterápicos (16).

O Guaco possui, em sua composição, metabólitos secundários tais como óleos essenciais, estigmasterol, taninos hidrolisáveis, flavonoides e saponina, além de cumarina e do ácido caurenoico, com propriedades farmacológicas descritas na literatura. Seu principal constituinte é a cumarina-2H-1-benzopiran-2-ona. A cumarina está presente principalmente nas folhas, e apresenta atividade broncodilatadora, expectorante, anti-inflamatória e antialérgica, tornando o Guaco um importante fitoterápico contra asma e bronquite (17).

Porém, os trabalhos encontrados nessa revisão, são todos pré-clínicos, dessa forma, seu uso deve ser feito com cautela.
Os Quadros 3 e 4 mostram as pesquisas sobre $C y$ nara scolymus e Solanum dulcamara, principais espécies utilizadas na Argentina

Cynara scolymus, conhecida como Alcachofra, pertence à família Asteraceae e é oriunda do Mediterrâneo. Porém, é encontrada em diversas partes do mundo, por ser utilizada para fins medicinais e também alimentícios (18). Possui em sua composição química cinarina, sais minerais, mucilagem, pectina, tanino, ácidos orgânicos, componentes flavônicos, vitaminas A, B1, B2 e C, entre outros (19). A alcachofra é uma das mais antigas plantas cultivadas no mundo, e seus extratos, obtidos a partir de diferentes partes (folhas, frutos e raízes), têm sido utilizados como medicamentos há décadas (20).

Devido a seu uso ser muito antigo, como fitoterápico ou alimento, possui inúmeros trabalhos sobre seu uso. No Quadro 3 estão descritos alguns estudos pré-clínicos e clínicos mais atuais, demonstrando principalmente os benefícios hepáticos e antiproliferativos de seu consumo.

É uma planta hepatoprotetora com função colerética e colagoga, e seu extrato foi liberado para produção de medicamentos fitoterápicos no Brasil, sem a necessidade de testes toxicológicos específicos, por ser usado há décadas e ter sua eficácia comprovada (21). 
El Senousy e cols. (2014) observaram diferenças na composição de folhas de alcachofra obtidas de três lugares, coletadas em diferentes estágios de desenvolvimento (22). Foi observada uma clara distinção entre elas, sendo um alerta de que a produção de matéria-prima deve ser feita com cautela, pois a idade da folha também leva a uma alteração na produção de metabólitos secundários (flavonoides e ácidos cafeoilquínicos). $\mathrm{O}$ uso das folhas superiores é o ideal para produção de produtos derivados dessa espécie.

Quadro 3. Estudos pré-clínicos e clínicos de Cynara scolymus L (2011-2016)

\begin{tabular}{|c|c|c|}
\hline Autor (ano & Origem & Objetivo \\
\hline \multicolumn{3}{|r|}{ Cynara scolymus } \\
\hline Colak e cols. (73) & Turquia & $\begin{array}{l}\text { Avaliação do efeito no estresse } \\
\text { oxidativo e lesão hepática }\end{array}$ \\
\hline Mustafa e cols. (74) & Egito & $\begin{array}{l}\text { Avaliação do potencial benéfico } \\
\text { sobre a toxicidade induzida por } \\
\text { doxorrubicina }\end{array}$ \\
\hline Mileo e cols. (75) & Itália & $\begin{array}{l}\text { Avaliação do efeito antiprolifera- } \\
\text { tivo e de quimioprevenção }\end{array}$ \\
\hline Pulito e cols. (76) & Itália & $\begin{array}{l}\text { Avaliação do efeito antitumoral } \\
\text { in vivo e in vitro em mesotelioma }\end{array}$ \\
\hline Morsy e Kamel (77) & Egito & $\begin{array}{l}\text { Avaliação do efeito protetor con- } \\
\text { tra lesão hepática causada por } \\
\text { paracetamol }\end{array}$ \\
\hline Rondanelli e cols. (19) & Itália & $\begin{array}{l}\text { Investigação da eficácia da su- } \\
\text { plementação no padrão de glico- } \\
\text { se em pacientes com sobrepeso }\end{array}$ \\
\hline Magielse e cols. (29) & Bélgica & $\begin{array}{l}\text { Avaliação da atividade antioxi- } \\
\text { dante in vivo }\end{array}$ \\
\hline
\end{tabular}

De acordo com a bula do medicamento fitoterápico Alcachofra (23), este possui ação colagoga, estimulando a secreção da bile pela vesícula biliar para o duodeno e ação colerética, estimulando a produção de bile pelo fígado. Assim sendo, facilita a digestão de alimentos gordurosos. Segundo Rondanelli e cols. (2013) os efeitos farmacológicos e terapêuticos da alcachofra no fígado são conhecidos desde o século XVII. E no século passado estudos confirmaram as propriedades estimulantes do extrato de alcachofra no fígado e vesícula biliar (20).

Noldin e cols (2003) avaliaram as folhas de $C$. scolymus provenientes de Curitiba (PR) e identificaram

\section{Tipo de estudo \\ Atividade biológica encontrada}

Apresentou efeito curativo sobre lesão hepática e estresse oxidativo, reduzindo a peroxidação lipídica

Pré-clínico: Ratos machos

Pré-clínico: Ratos machos

Pré-clínico: In vitro - Linhagem de célula

Pré-clínico: Linhagens celulares MST0-211H, MPP-89, NCI-H28 e HMC; camundongos fêmeas CD1

Pré-clínico: Ratos

Clínico: pacientes com sobrepeso

Pré-clínico: ratos indu-

zidos à diabetes por es- Redução do estresse oxidativo treptozotocina
Melhora nos parâmetros hepáticos e renais, up-regulation de enzimas protetoras e down-regulation do estresse oxidativo

Nossos resultados sugerem que os polifenóis de alcachofra pode ser uma ferramenta promissora na dieta seja na quimioprevenção do câncer e/ou no tratamento do câncer como uma terapia não convencional, adjuvante.

Exerceu efeito antitumoral tanto nas linhagens como nos camundongos. Reduziu o crescimento, migração e enxerto de tumor em células. Reduziu o crescimento de tumores xenoenxertados nos animais.

Pré-tratamento reestabeleceu as concentrações de glutationa (GSH) hepática, reverteu parâmetros de estresse oxidativo, danos no DNA, e necrose induzidos por paracetamol

Melhora da glicemia de jejum, modelo de avaliação da homeostase (HOMA) e padrão lipídico. substâncias como flavonoides (que possuem várias ações farmacológicas como antibacteriana, anti-inflamatória, antioxidante, hipolipidêmica), cinaropicrina e apenas traços de cinarina, a qual é encontrada em maior quantidade em alcachofras da Europa (18). A cinaropicrina, além de propriedades antitumorais, antimicrobianas e antifúngicas, pode causar dermatite alérgica, inibição da secreção de plaquetas e efeitos citotóxicos. Os autores alertaram sobre a importância da presença da lactona sesquiterpênica cinaropicrina como componente majoritário, embora não tenha exibido ação citotóxica neste estudo, é considerado neurotóxico e pode comprometer o uso da alcachofra no Brasil. 
Quadro 4. Estudos pré-clínicos e clínicos de Solanum dulcamara (2011-2016)

\begin{tabular}{|c|c|c|c|c|}
\hline Autor (ano) & Origem & Objetivo & Tipo de estudo & Atividade biológica encontrada \\
\hline \multicolumn{5}{|c|}{ Espécie Solanum dulcamara (Dulcamara) } \\
\hline Sharma (78) & Índia & $\begin{array}{l}\text { Avaliação da atividade antimicro- } \\
\text { biana do extrato etanólico em bac- } \\
\text { térias Gram-positivas e negativas }\end{array}$ & $\begin{array}{l}\text { Pré-clínico: in vitro - } \\
\text { bactérias Gram-posi- } \\
\text { tivas e negativas }\end{array}$ & $\begin{array}{l}\text { Apresentou atividade antimicrobiana, } \\
\text { principalmente na cepa S. viridans, bac- } \\
\text { téria Gram-positiva }\end{array}$ \\
\hline Rajashekhar e cols. (79) & Índia & $\begin{array}{l}\text { Investigação da atividade hepa- } \\
\text { toprotetora do extrato etanólico em } \\
\text { ratos induzidos à hepatotoxixidade } \\
\text { por paracetamol }\end{array}$ & $\begin{array}{l}\text { Pré-clínico: Ratos al- } \\
\text { binos e camundongos }\end{array}$ & Atividade hepatoprotetora moderada \\
\hline Mutlu e cols. (80) & Turquia & $\begin{array}{l}\text { Avaliação da atividade antitumoral } \\
\text { e antimicrobiana da planta cultiva- } \\
\text { da no campo e in vitro }\end{array}$ & $\begin{array}{l}\text { Pré-clínico: } \\
\text { In vitro em células e } \\
\text { ensaio com dez cepas } \\
\text { de bactérias }\end{array}$ & $\begin{array}{l}\text { Plantas cultivadas no campo apresenta- } \\
\text { ram melhor atividade antitumoral, bem } \\
\text { como o extrato metanólico foi melhor } \\
\text { que o aquoso. No ensaio antimicrobiano, } \\
\text { o extrato metanólico da planta cultivada } \\
\text { no campo foi o mais efetivo, e apresen- } \\
\text { tou atividade contra S. epidermidis, S. } \\
\text { aureus, K. pneumonia, S. typhimurium e } \\
\text { S. marcescens }\end{array}$ \\
\hline
\end{tabular}

Por possuir várias propriedades terapêuticas e praticamente não ter efeitos colaterais, a Alcachofra é recomendada não só para doenças hepáticas, mas também na prevenção da aterosclerose e hiperlipidemia (24). É também usada na medicina popular como hepatoprotetora, no tratamento de doenças cardiovasculares e na inibição da biossíntese do colesterol. Botsaris e Alves (2007) observaram que os flavonoides e polifenois presentes nos extratos de C. scolymus são responsáveis pela sua ação antioxidante (25).

Mattos (2014) avaliou os possíveis efeitos tóxicos do extrato seco de C. scolymus em ratos, e observou que não promoveu toxicidade geral em ratos tratados subagudamente, porém as fêmeas tratadas apresentaram redução no ganho de peso, diminuição do peso uterino e fetal, menor comprimento fetal e queda do número de fetos vivos por ninhada, evidenciando que durante a gestação, apresenta toxicidade fetal (21).

Heidarian e Rafieian-Kopaei (2013) avaliaram o efeito protetor do extrato hidroetanólico de alcachofra em ratos que receberam chumbo acrescido na dieta 500 $\mathrm{mg} / \mathrm{kg}$ por seis semanas (26). O tratamento concomitante de $300 \mathrm{mg} / \mathrm{kg} / \mathrm{dia}$ do extrato por gavagem levou à diminuição significativa de chumbo sérico, triglicerídeos, lipoproteína de densidade muito baixa (VLDL), alanina aminotransferase (ALT), aspartato aminotransferase (AST) e fosfatase alcalina. Os autores evidenciaram que o extrato de alcachofra possui propriedades quelantes apropriadas para reduzir os níveis desse metal pesado no sangue em ratos envenenados com chumbo.

O tratamento multidirecional é um fato documentado e essa espécie é utilizada para o tratamento de diversas patologias. Há evidências farmacológicas e clínicas do uso de C. scolymus na síndrome do intestino irritável, diminuindo os sintomas, sendo que $96 \%$ dos pacientes relataram que o extrato foi melhor ou igual às terapias realizadas anteriormente. Ainda, o extrato das folhas da alcachofra possui grande potencial antioxidante, sendo também usado no tratamento de desordens dispépticas, hepáticas, obesidade e hipercolesterolemia. A atividade antiespasmódica no íleo em cobaias e a prevenção de lesões na mucosa gástrica induzida por etanol e estresse, também foram demonstradas $(27,28)$.

Magielse e cols (2014) observaram que o extrato aquoso das folhas da alcachofra apresentou potencial antioxidante em ratos com Diabetes tipo 1 induzida por streptozotocina via intraperitoneal, com tratamento por 3 semanas após a indução, em doses de $0,2 \mathrm{~g} / \mathrm{kg}$ e $1 \mathrm{~g} /$ $\mathrm{kg}$, via suplementação oral (29).

Ao contrário da Alcachofra, muito estudada e com inúmeros relatos na literatura, para Dulcamara $(S . d u l$ camara) há poucos relatos, encontrados nessa revisão (Quadro 4). É conhecida popularmente como doce-amarga ou unha-de-cão, pertence à família Solanaceae, e é indicada para problemas respiratórios e doenças na pele, como celulite, dermatose, eczema, erupções cutâneas, entre outras (30).

Solanum dulcamara é nativa da Eurásia, podendo ocorrer como invasora nos Estados Unidos. Também é encontrada em margens de lagos ou topos de dunas costeiras. O principal agente de dispersão são aves, que se alimentam dos frutos vermelhos, mas pode ocorrer também pela água (31). É uma das plantas mais utilizadas 
na Argentina, porém é tóxica, podendo paralisar o sistema nervoso central se utilizada em excesso, reduzindo os batimentos cardíacos, a respiração, temperatura, podendo causar delírio, convulsões e até a morte (30). Deve haver grande cautela em seu uso, principalmente via oral.

Quadro 5. Estudos pré-clínicos e clínicos de Peumus boldus Mol. (Boldo) (2011-2016).

\begin{tabular}{|c|c|c|c|c|}
\hline Autor (ano & Origem & Objetivo & Tipo de estudo & Atividade biológica encontrada \\
\hline \multicolumn{5}{|c|}{ Peumus boldus Mol. (Boldo) } \\
\hline Santos e cols. (81) & Brasil & $\begin{array}{l}\text { Avaliação da atividade antifún- } \\
\text { gica do óleo essencial }\end{array}$ & Pré-clínico: in vitro, fungo & $\begin{array}{l}\text { Boa atividade antifúngica, sendo eficaz } \\
\text { na inibição de leveduras da espécie Can- } \\
\text { dida albicans }\end{array}$ \\
\hline Falé e cols. (33) & Portugal & $\begin{array}{l}\text { Avaliação da atividade inibitó- } \\
\text { ria do extrato aquoso quanto à } \\
\text { inibição de acetilcolinesterase, } \\
\text { atividade antioxidante e toxi- } \\
\text { cidade in vitro }\end{array}$ & $\begin{array}{l}\text { Pré-clínico: In vitro, li- } \\
\text { nhagens celulares CACO-2 } \\
\text { e HeLa }\end{array}$ & $\begin{array}{l}\text { Apresentou atividade antioxidante, não } \\
\text { apresentou toxicidade em células intes- } \\
\text { tinais CACO-2, porém mostrou efeito an- } \\
\text { tiproliferativo em células HeLa }\end{array}$ \\
\hline Klimaczewski e cols. (34) & Brasil & $\begin{array}{l}\text { Avaliação da atividade antioxi- } \\
\text { dante do extrato aquoso e de } \\
\text { boldina in vitro em mitocôn- } \\
\text { dria hepática }\end{array}$ & $\begin{array}{l}\text { Pré-clínico: in vitro, mi- } \\
\text { tocôndrias hepáticas de } \\
\text { ratos }\end{array}$ & $\begin{array}{l}\text { Apresentou propriedades antioxidantes } \\
\text { contra disfunção mitocondrial hepática } \\
\text { induzida pelo ferro e a boldina atividade } \\
\text { modesta }\end{array}$ \\
\hline Mondal e cols. (82) & Índia & $\begin{array}{l}\text { Avaliação da atividade do ex- } \\
\text { trato etanólico usado simulta- } \\
\text { neamente com cisplatin para } \\
\text { avaliar redução de citotoxici- } \\
\text { dade sem afetar o efeito anti- } \\
\text { cancer do fármaco }\end{array}$ & $\begin{array}{l}\text { Pré-clínico: in vitro, linha- } \\
\text { gens de células com cân- } \\
\text { cer A549, HeLa e HepG2, e } \\
\text { linhagem de célula hepá- } \\
\text { tica normal (WRL-68) }\end{array}$ & $\begin{array}{l}\text { Melhorou viabilidade das células nor- } \\
\text { mais, e não teve efeito na viabilidade } \\
\text { das cancerígenas. Dose baixa do extra- } \\
\text { to pode ser beneficamente utilizado em } \\
\text { combinação com a cisplatina para redu- } \\
\text { zir a sua toxicidade, sem prejudicar o } \\
\text { efeito anticâncer da cisplatina }\end{array}$ \\
\hline Pastene e cols. (83) & Chile & $\begin{array}{l}\text { Investigação do efeito anti- } \\
\text {-Helicobacter pylori do extrato } \\
\text { aquoso }\end{array}$ & $\begin{array}{l}\text { Pré-clínico: in vitro, Cultu- } \\
\text { ra de Helicobacter pylori e } \\
\text { células AGS }\end{array}$ & $\begin{array}{l}\text { Elevada atividade inibitória contra Heli- } \\
\text { cobacter pylori urease e efeito anti ade- } \\
\text { são devido à proantocianidinas deriva- } \\
\text { das de catequina }\end{array}$ \\
\hline
\end{tabular}

Quadro 6. Estudos pré-clínicos e clínicos de Borago officinalis (Borragem) (2011-2016).

\begin{tabular}{|c|c|c|c|c|}
\hline Autor (ano) & Origem & Objetivo & Tipo de estudo & Atividade biológica encontrada \\
\hline \multicolumn{5}{|c|}{ Espécie Borago officinalis (Borragem) } \\
\hline Shahraki e cols. (84) & Irã & $\begin{array}{l}\text { Avaliação do efeito anti- } \\
\text { nociceptivo do extrato hi- } \\
\text { droalcoolico em modelo de } \\
\text { formalina }\end{array}$ & $\begin{array}{l}\text { Pré-clínico: Ratos machos } \\
\text { Wistar }\end{array}$ & $\begin{array}{l}\text { Redução do comportamento de dor agu- } \\
\text { da e crônica }\end{array}$ \\
\hline $\begin{array}{l}\text { Zargooshnia e cols. } \\
\text { (85) }\end{array}$ & Irã & $\begin{array}{l}\text { Avaliação do efeito neuro- } \\
\text { protetor protetor do extrato } \\
\text { em animais }\end{array}$ & $\begin{array}{l}\text { Pré-clínico:Ratos machos } \\
\text { Wistar }\end{array}$ & $\begin{array}{l}\text { Pode atuar melhorando a disfunção cog- } \\
\text { nitiva na doença de Alzheimer }\end{array}$ \\
\hline $\begin{array}{l}\text { Ghahremanitamadon } \\
\text { e cols. (37) }\end{array}$ & Irã & $\begin{array}{l}\text { Avaliação do efeito do extra- } \\
\text { to no comprometimento da } \\
\text { memoria induzido por beta } \\
\text { amiloide }\end{array}$ & $\begin{array}{l}\text { Pré-clínico: Ratos machos } \\
\text { Wistar }\end{array}$ & $\begin{array}{l}\text { Melhorou perfil antioxidante no hipo- } \\
\text { campo, e a disfunção de aprendizagem, } \\
\text { podendo ser benéfico em casos de per- } \\
\text { turbações da memória }\end{array}$ \\
\hline Arm e cols. (86) & Estados Unidos & $\begin{array}{l}\text { Avaliação do efeito da su- } \\
\text { plementação óleos (Borra- } \\
\text { gem e Echium plantagineum } \\
\text { alternadamente) no perfil de } \\
\text { ácidos graxos e leucotrienos } \\
\text { em asmáticos leves }\end{array}$ & $\begin{array}{l}\text { Clínico: Pacientes asmá- } \\
\text { ticos }\end{array}$ & $\begin{array}{l}\text { Atenuou a produção de leucotrienos de } \\
\text { forma consistente, reduzindo a inflama- } \\
\text { ção }\end{array}$ \\
\hline Tso e cols. (87) & Estados Unidos & $\begin{array}{l}\text { Comparação do efeito da } \\
\text { suplementação com óleo de } \\
\text { borragem com óleo de cár- } \\
\text { tamo }\end{array}$ & $\begin{array}{l}\text { Pré-clínico: Ratos machos } \\
\text { e fêmeas Sprague-Dawley }\end{array}$ & $\begin{array}{l}\text { Não demonstrou toxicidade e os óleos } \\
\text { tiveram efeitos similares no crescimen- } \\
\text { to, metabolismo e parâmetros bioquí- } \\
\text { micos }\end{array}$ \\
\hline Wauquier e cols. (88) & França & $\begin{array}{l}\text { Análise do impacto de óleo } \\
\text { de borragem e de peixe no } \\
\text { aparelho locomotor e enve- } \\
\text { lhemcimento }\end{array}$ & $\begin{array}{l}\text { Pré-clínico: Camundongos } \\
\text { fêmeas de senescência } \\
\text { acelerada (SamP8), e ca- } \\
\text { mundongos de senescência } \\
\text { acelerada (SamR1) }\end{array}$ & $\begin{array}{l}\text { Efeito anti-inflamatório e de restaura- } \\
\text { ção óssea em modelo de osteoporose } \\
\text { senil }\end{array}$ \\
\hline
\end{tabular}


Os estudos sobre a dulcamara são escassos, mas os encontrados no presente estudo, revelam as atividades antimicrobiana e antitumoral da espécie.

Os Quadros 5 e 6 trazem os resultados sobre as espécies Peumus boldus Mol. (Boldo) e Borago officinalis (Borragem).

O Boldo (Peumus boldus Mol.) é uma planta medicinal nativa da zona Central do Chile. Suas folhas foram descritas no final do séc. XIX em diversas farmacopeias europeias, e continua mantida nas atuais. É utilizado entre os indígenas chilenos para indigestão, disfunções hepáticas e reumatismo, desde muito antes da chegada dos conquistadores espanhóis (32).

Estudos encontrados sobre a espécie encontram-se descritos no Quadro 5, no qual destacam-se as pesquisas pré-clínicas mostrando seus efeitos em relação à atividade antifúngica, antioxidante, hepatoprotetora e antimicrobiana. Vale ressaltar que foram poucos os estudos pré-clínicos encontrados, e nenhum estudo clínico foi evidenciado nas bases de dados pesquisadas, nos últimos 5 anos.
O Boldo possui importante ação colérica e colagoga, bem como efeito sedativo, hepatoprotetor e anti-inflamatório. A boldina, um alcaloide presente na espécie, o ascaridol, presente no óleo essencial e outros flavonoides, são tidos como os constituintes ativos da planta (32).

Segundo Falé e cols. (2012), o Boldo possui em sua composição flavonoides glicosilados, embora a boldina e outros derivados de alcaloides aporfínicos, também tenham sido detectados em quantidades pequenas (33).

O efeito do extrato aquoso do Boldo no auxílio do processo de digestão pode ser explicado pela inibição da acetilcolinesterase, enzima encontrada nas junções neuromusculares do trato gastrointestinal, a qual, quando inibida, aumenta a motilidade intestinal. A atividade do Boldo continua intacta ao longo da digestão pelo trato gastrointestinal (33).

Klimaczewski e cols. (2014) sugeriram que o efeito hepatoprotetor do extrato aquoso de $P$. boldus é mediado pela redução do ferro, e que a planta possui componentes terapêuticos antioxidantes multifuncionais, que provavelmente funcionam em sinergia para gerar esse efeito (34).

Quadro 7. Estudos pré-clínicos e clínicos de Aloe vera (Aloe) (2011-2016).

\begin{tabular}{|c|c|c|c|c|}
\hline Autor (ano & Origem & Objetivo & Tipo de estudo & Atividade biológica encontrada \\
\hline \multicolumn{5}{|c|}{ Aloe vera (Aloe) } \\
\hline Baradaran e cols. (89) & Irã & $\begin{array}{l}\text { Avaliação da atividade an- } \\
\text { tioxidante e preventiva do } \\
\text { extrato em animais induzi- } \\
\text { dos à nefrotoxicidade }\end{array}$ & $\begin{array}{l}\text { Pré-clínico: Ratos Wistar } \\
\text { machos }\end{array}$ & $\begin{array}{l}\text { Proteção significativa nas células renais } \\
\text { e danos tubulares induzidos por genta- } \\
\text { micina }\end{array}$ \\
\hline Huseini e cols. (90) & Irã & $\begin{array}{l}\text { Avaliação do efeito antihi- } \\
\text { perglicemico e anti-hiper- } \\
\text { colesterolêmico }\end{array}$ & $\begin{array}{l}\text { Clínico: Pacientes entre } \\
40-60 \text { anos com diabetes } \\
\text { tipo } 2 \text { e dislipidêmicos }\end{array}$ & $\begin{array}{l}\text { Redução da glicemia, hemoglobina glica- } \\
\text { da, colesterol total e LDL-colesterol, sem } \\
\text { efeitos adversos nos demais parâmetros } \\
\text { bioquímicos }\end{array}$ \\
\hline $\begin{array}{l}\text { Sudarshan e cols. } \\
(40)\end{array}$ & Índia & $\begin{array}{l}\text { Avaliação do efeito do gel } \\
\text { (tópico) no tratamento de } \\
\text { fibrose submucosa oral }\end{array}$ & $\begin{array}{l}\text { Clínico: Pacientes com } \\
\text { fibrose submucosa oral }\end{array}$ & $\begin{array}{l}\text { Reduziu sensação de ardor, melhorou } \\
\text { abertura da boca e flexibilidade da bo- } \\
\text { checha }\end{array}$ \\
\hline Dinesh e cols. (91) & Não encontrado & $\begin{array}{l}\text { Avaliação do efeito antimi- } \\
\text { crobiano }\end{array}$ & Pré-clínico: Bactérias & $\begin{array}{l}\text { Apresentou efeito bactericida contra Ba- } \\
\text { cillus subtilis, Klebsiella pneumoniae, e } \\
\text { Salmonella typhi }\end{array}$ \\
\hline $\begin{array}{l}\text { Vijayalakshmi e cols. } \\
\text { (92) }\end{array}$ & Índia & $\begin{array}{l}\text { Avaliação do efeito anti- } \\
\text {-inflamatório em células } \\
\text { mononucleares }\end{array}$ & $\begin{array}{l}\text { Pré-clínico: células mo- } \\
\text { nonucleares de sangue } \\
\text { periférico isolados de } \\
\text { sangue humano (PBMC) }\end{array}$ & $\begin{array}{l}\text { Efeito anti-inflamatório, causou down-re- } \\
\text { gulation de MMP-9 }\end{array}$ \\
\hline $\begin{array}{l}\text { Rezazadeh e cols. } \\
\text { (93) }\end{array}$ & & $\begin{array}{l}\text { Avaliação do efeito anti- } \\
\text {-viral do gel em linhagem } \\
\text { celular Vero }\end{array}$ & $\begin{array}{l}\text { Pré-clínico: Linhagem } \\
\text { celular Vero }\end{array}$ & $\begin{array}{l}\text { Atividade inibitória no crescimento de } \\
\text { Herpes simplex (HSV-1) }\end{array}$ \\
\hline $\begin{array}{l}\text { Werawatganon e cols. } \\
(94)\end{array}$ & Tailândia & $\begin{array}{l}\text { Avaliação do efeito prote- } \\
\text { tor do gel em patologias } \\
\text { gástricas }\end{array}$ & $\begin{array}{l}\text { Pré-clínico: Ratos Spra- } \\
\text { gue-Dawley machos }\end{array}$ & $\begin{array}{l}\text { Atenuou a gastropatia induzida por indo- } \\
\text { metacina, reduzindo o estresse oxidativo, } \\
\text { inflamação e melhorando a da histopato- } \\
\text { logia gástrica }\end{array}$ \\
\hline Guven e cols. (95) & Turquia & $\begin{array}{l}\text { Avaliação do efeito neuro- } \\
\text { protetor na isquemia-reper- } \\
\text { fusão do nervo ciático }\end{array}$ & $\begin{array}{l}\text { Pré-clínico: Ratos Wistar } \\
\text { machos }\end{array}$ & $\begin{array}{l}\text { Efetivo como neuroprotetor, pelo efeito } \\
\text { anti-inflamatório e antioxidante }\end{array}$ \\
\hline $\begin{array}{l}\text { Sahebjamee e cols. } \\
\text { (96) }\end{array}$ & Não encontrado & $\begin{array}{l}\text { Avaliação do efeito do gar- } \\
\text { garejo em mucosite oral de } \\
\text { pacientes em tratamento } \\
\text { radioterápico }\end{array}$ & $\begin{array}{l}\text { Clínico: pacientes com } \\
\text { câncer de cabeça ou pes- } \\
\text { coço }\end{array}$ & $\begin{array}{l}\text { Aliviou a severidade da mucosite oral } \\
\text { assim como benzidamina, e sem efeitos } \\
\text { adversos }\end{array}$ \\
\hline
\end{tabular}


A Borragem (Borago officinalis) (Quadro 6) é uma planta medicinal cultivada para uso culinário e terapêutico, comercializada principalmente como óleo de borragem. É rica em ácido-gama-linolênico (26-38 \%), sendo utilizada como suplemento. Contudo, também possui outros ácidos graxos na composição como ácido linoleico (35-38 \%) e ácido oleico (16-20\%) (35). Outra forma de consumo dessa espécie é por meio de infusão de suas flores, a qual possui efeito hipocolesterolêmico (36).

Essa espécie, também conhecida como flor da estrela, pertence à família Boraginaceae, é originária da Síria e natural da região do Mediterrâneo, sendo encon- trada também na Ásia, Europa, Norte da África e América do Sul (36).

A composição química primária das folhas e flores é constituída de mucilagens, taninos, saponinas, óleo essencial, alcaloides, vitamina $\mathrm{C}$, cálcio e potássio (36). Estudos fitoquímicos mostraram que $B$. officinalis é composta por taninos, reninas, ácido ascórbico, beta-caroteno, niacina, riboflavina, ácido rosmarínico e flavonoides. Porém, é considerada como fonte de ácido gama-linolênico, o qual possui efeitos benéficos no envelhecimento do cérebro, melhorando também a memória (37).

Quadro 8. Estudos pré-clínicos e clínicos de Passiflora edulis (maracujá) (2011-2016).

\begin{tabular}{|c|c|c|c|c|}
\hline Autor (ano & Origem & Objetivo & Tipo de estudo & Atividade biológica encontrada \\
\hline \multicolumn{5}{|c|}{ Passiflora edulis (Maracujá) } \\
\hline Otify e cols. (43) & Egito & $\begin{array}{l}\text { Avaliação do efeito ansiolítico } \\
\text { do extrato etanólico e frações }\end{array}$ & Pré-clínico: in vivo & $\begin{array}{l}\text { Maiores efeitos ansiolíticos nas frações } \\
\text { butanol e clorofórmio }\end{array}$ \\
\hline Devaki e cols. (44) & India & $\begin{array}{l}\text { Avaliação da toxicidade do } \\
\text { extrato aquoso das folhas em } \\
\text { animais }\end{array}$ & Pré-clínico: Ratos Wistar & $\begin{array}{l}\text { Não apresentou toxicidade aguda, } \\
\text { mostrando-se segura em até } 2000 \mathrm{mg} / \\
\mathrm{kg} \text {, sem efeitos nefrotóxicos e hepato- } \\
\text { tóxicos }\end{array}$ \\
\hline Klein e cols. (97) & Brasil & $\begin{array}{l}\text { Avaliação do efeito sedativo } \\
\text { do extrato aquoso das folhas e } \\
\text { pericarpo em camundongos }\end{array}$ & $\begin{array}{l}\text { Pré-clínico: Camun- } \\
\text { dongos }\end{array}$ & $\begin{array}{l}\text { Redução da atividade locomotora dos } \\
\text { animais e efeito sedativo }\end{array}$ \\
\hline Silva e cols. (45) & Brasil & $\begin{array}{l}\text { Avaliação da atividade antioxi- } \\
\text { dante do extrato aquoso }\end{array}$ & $\begin{array}{l}\text { Pré-clínico: in vivo, } \\
\text { Ratos Wistar machos }\end{array}$ & $\begin{array}{l}\text { Atividade antioxidante, melhorando o } \\
\text { poder antioxidante e reduzindo a peroxi- } \\
\text { dação lipídica nos órgãos }\end{array}$ \\
\hline Dzotam e cols. (98) & Camarões & $\begin{array}{l}\text { Avaliação do efeito antimicro- } \\
\text { biano }\end{array}$ & $\begin{array}{l}\text { Pré-clínico: Bacterias } \\
\text { Gram-negativas }\end{array}$ & Apresentou efeito antimicrobiano \\
\hline $\begin{array}{l}\text { Kandandapani e } \\
\text { cols. (99) }\end{array}$ & Malásia & $\begin{array}{l}\text { Avaliação do efeito antidiabéti- } \\
\text { co do extrato }\end{array}$ & Pré-clínico: Ratos Wistar & $\begin{array}{l}\text { Efeito antidiabético, controlando a gli- } \\
\text { cose sanguínea, e efeito antioxidante }\end{array}$ \\
\hline Cazarin e cols. (42) & Brasil & $\begin{array}{l}\text { Avaliação do efeito em animais } \\
\text { induzidos à colite }\end{array}$ & Pré-clínico: in vivo & $\begin{array}{l}\text { Foi observada modulação da microbiota } \\
\text { e melhora da resposta antioxidante }\end{array}$ \\
\hline Corrêa e cols. (100) & Brasil & $\begin{array}{l}\text { Avaliação do efeito da fibra do } \\
\text { mesocarpo nos parâmetros bio- } \\
\text { químicos de animais induzidos } \\
\text { à diabetes }\end{array}$ & $\begin{array}{l}\text { Pré-clínico: Ratos Wistar } \\
\text { machos }\end{array}$ & $\begin{array}{l}\text { Efeito hipoglicemiante, e redução de } \\
\text { triglicerídeos, VLDL, insulina e leptina }\end{array}$ \\
\hline
\end{tabular}

É utilizada para regular o metabolismo e o sistema hormonal, indicada para amenizar sintomas da menopausa, como as ondas de calor. Ainda, é usada para aliviar e curar resfriados, bronquite e infecções respiratórias, por ter ação anti-inflamatória (36). Também é indicada para tratar diabetes, problemas cardíacos, artrite, eczema e esclerose múltipla (35). A Borragem atua na restauração das glândulas adrenais, sendo uma aplicação interessante após uso de esteroides e cortisona (36).

Nos Quadros 7 e 8 estão descritos estudos encontrados sobre Aloe vera L e Passiflora edulis
Aloe vera é uma planta utilizada globalmente na medicina popular, para o tratamento de diversas patologias, entre elas, doenças de pele. $\mathrm{O}$ gel dessa planta faz parte da composição de cosméticos, produtos medicinais e suplementos alimentares (38). Destaca-se que a aloe é muito estudada, principalmente em relação ao potencial anti-inflamatório que apresenta, tanto via oral como tópica.

Análises químicas mostram que possui vários polissacarídeos e compostos fenólicos, destacando as antraquinonas. Sua ingestão em preparações é associada 
a sintomas como diarreia, hipocalemia, insuficiência renal, melanose coli, fototoxicidade e reações de hipersensibilidade (39).

Possui propriedades anti-inflamatórias; os esterois presentes nessa espécie geram forte efeito inibitório de inflamação aguda, similar à cortisona, porém sem efeitos colaterais. Acredita-se que a aloe tenha mecanismo parecido com o ácido acetilsalicílico, bloqueando os efeitos da prostaglandina, porém isso ainda não foi comprovado (40).

A aloe é também utilizada em diversos produtos alimentícios e em cosméticos, porém, a exposição em excesso gera preocupações em relação a sua segurança, pelo potencial tóxico e carcinogênico que apresenta (39)

Apesar de muito consumida, e alguns estudos demonstrarem que não foram encontrados dados de toxicidade, Guo e Mei (2016), relataram que o extrato da folha de Aloe vera também mostra clara evidência carcinogênica em ratos (39).

No Brasil, a aloe pode ser utilizada apenas para uso tópico, e seu uso oral ou como alimento não é permitido. Destacam-se os derivados antracênicos, que estão presentes nessa espécie, possuem diversos efeitos maléficos ao organismo, como efeitos hepatotóxicos, nefrotóxicos e lesões gastrointestinais (41).

Pode ser observado que os estudos sobre essa espécie (Aloe vera) em relação à segurança, aos efeitos colaterais e toxicidade são contraditórios, dessa forma, o profissional deve levar em consideração esses fatos, pois a segurança do paciente é primordial e para que uma espécie seja prescrita ou indicada, deve-se ter certeza da segurança das dosagens e formas de utilização para não colocar em risco a saúde do paciente.

Maracujá (Quadro 8) é o nome popular dado a várias espécies pertencentes ao gênero Passiflora, no qual há mais de 500 espécies distribuídas globalmente. O Brasil é o maior detentor, com mais de 79 espécies. A espécie Passiflora edulis, chamada de maracujá azedo ou amarelo, é o mais comercializado e produzido, e representa cerca de $95 \%$ dos pomares, sendo utilizado principalmente para o cultivo de sucos e polpas (42). Passiflora edulis, juntamente com outras espécies do gênero Passiflora, tem sido reportada como sedativa e utilizada para o tratamento de doenças do sistema nervoso central (43).

$E$ uma planta medicinal de uso popular, utilizada no tratamento de diversas patologias. É encontrada em locais com temperaturas mais elevadas e regiões tropicais. A polpa da fruta possui efeito estimulante e tônico, além de anticarcinogênico. O extrato das flores possui atividade sedativa e hipnótica, enquanto as partes aéreas e hastes demonstram ação anti-inflamatória, ansiolítica, antitumoral, antimicrobiana e antioxidante (44). É uma fonte rica de compostos bioativos, como polifenois. Silva e cols. (2013) identificaram três flavonoides no extrato aquoso dessa planta, sendo estes vitexina, isovitexina e isorientina (45).

De acordo com o Quadro 8, pode ser observado que o encontrado na literatura, comprovado por meio de pesquisas pré-clínicas, confirma o uso popular e medicinal da espécie $P$. edulis, a qual demonstrou atividade sedativa, antioxidante, antidiabética, sem causar toxicidade em até $2000 \mathrm{mg} / \mathrm{kg}$.

No Quadro 9 são apresentados os achados sobre Hedera helix. Pode ser observado que a maior parte dos estudos refere-se à comprovação do seu efeito no trato respiratório, como é popularmente utilizada.

Hedera helix (Hera) pertence à família Araliacea e é cultivada ornamentalmente. Pode ser encontrada escalando muros e cobrindo paredes com suas folhas, e. Seu extrato possui atividade antioxidante, antiproliferativa, antiespasmódica e antialergênica, além de ter sido relatada atividade contra problemas respiratórios (46). É uma espécie do Paquistão e possui como constituintes químicos alcaloides, terpenoides, saponinas e taninos (47).

O uso das folhas de Hera é antigo, sendo utilizada na medicina tradicional e contemporânea, por possuir efeito broncodilatador e antiespasmódico. Porém pode ter efeitos adversos, como estímulo do peristaltismo na musculatura lisa (48).

Aspectos Toxicológicos. Informações complementares medicinais devem ser incorporadas à prática clínica e educação do paciente e profissional de saúde, além de uma educação adequada sobre propriedades nutricionais. A consciência do uso generalizado de medicina complementar e alternativa por pessoas com distúrbios metabólicos são cruciais para os profissionais de saúde a fim de prevenir doenças (19).

Os medicamentos fitoterápicos estão sendo cada vez mais procurados e utilizados, o que aumenta a necessidade de um controle de qualidade rígido e eficaz, assegurando a utilização pelos pacientes (14).

Assim como os outros medicamentos, os fitoterápicos possuem riscos, e estudos sugerem possíveis reações adversas ou interações, como efeito carcinogênico, hepatotóxico e cardiotóxico (49). Apesar do crescente uso 
e comercialização de fitoterápicos de uma forma global, os estudos sobre a toxicidade dos mesmos, principalmente no Brasil, são poucos, assim como o controle de qualidade, que muitas vezes faz com que o consumidor esteja consumindo produtos adulterados ou contaminados, colocando-o em risco.

Quadro 9. Estudos pré-clínicos e clínicos de Hedera helix (2011-2016)

\begin{tabular}{|c|c|c|c|c|}
\hline Autor (ano) & Pais & Objetivo & Tipo de estudo & Atividade biológica encontrada \\
\hline \multicolumn{5}{|c|}{ Hedera helix (Hera) } \\
\hline Hocaoglu e cols. (101) & Turquia & $\begin{array}{l}\text { Avaliação do efeito via oral } \\
\text { na histopatologia pulmonar } \\
\text { em modelo de asma crônica }\end{array}$ & $\begin{array}{l}\text { Pré-clínico: Camundon- } \\
\text { gos BALB/C }\end{array}$ & $\begin{array}{l}\text { Reduziu o número de células caliciformes } \\
\text { e espessura da membrana basal }\end{array}$ \\
\hline Liu e cols. (102) & China & $\begin{array}{l}\text { Avaliação se composto iso- } \\
\text { lado (hederagenina) induz } \\
\text { apoptose em células de cân- } \\
\text { cer colorretal }\end{array}$ & $\begin{array}{l}\text { Pré-clínico: in vitro, } \\
\text { linhagem celular LoVo }\end{array}$ & $\begin{array}{l}\text { Inibiu a proliferação e induziu a apoptose } \\
\text { via intrínseca (mitocondrial) }\end{array}$ \\
\hline Song e cols. (103) & Coreia & $\begin{array}{l}\text { Avaliação da atividade an- } \\
\text { tiviral do extrato etanólico } \\
\text { (30\%) e da hederasaponina B } \\
\text { em Enterovírus } 71\end{array}$ & $\begin{array}{l}\text { Pré-clínico: in vitro, cé- } \\
\text { lulas Vero, linhagem de } \\
\text { células renais de macaco } \\
\text { verde africano }\end{array}$ & $\begin{array}{l}\text { Apresentou efeito antiviral significativa } \\
\text { nos subgêneros } \mathrm{C} 3 \text { e } \mathrm{C} 4 \text {, reduzindo efeito } \\
\text { citopático. }\end{array}$ \\
\hline Hooshyar e cols. (104) & Irã & $\begin{array}{l}\text { Avaliação do efeito do extrato } \\
\text { alcoólico sobre leishmaniose } \\
\text { cutânea }\end{array}$ & $\begin{array}{l}\text { Pré-clínico: camundon- } \\
\text { gos BALB/C }\end{array}$ & Não efeito anti-leishmaniose \\
\hline Anuradha (46) & Índia & $\begin{array}{l}\text { Avaliação do efeito anti-infla- } \\
\text { matório do extrato etanólico } \\
\text { in vivo modelo edema de pata }\end{array}$ & $\begin{array}{l}\text { Pré-clínico: camun- } \\
\text { dongos Swiss machos e } \\
\text { fêmeas }\end{array}$ & $\begin{array}{l}\text { Inibiu o edema em } 88,89 \% \text {, apresentando } \\
\text { efeito anti-inflamatório }\end{array}$ \\
\hline Uddin e cols. (47) & Paquistão & $\begin{array}{l}\text { Avaliação da atividade anti- } \\
\text { microbiana das frações }\end{array}$ & Pré-clínico: Bactérias & $\begin{array}{l}\text { Apresentou efeito antimicrobiano contra } \\
\text { E. coli, Staphylococcus aureus, Staphylo- } \\
\text { coccus epidermidis, Bacillus subtilis e } \\
\text { Klebsiella pneumonia }\end{array}$ \\
\hline Mendel e cols. (48) & Polônia & $\begin{array}{l}\text { Avaliação da atividade do ex- } \\
\text { trato e saponinas (A-hederina } \\
\text { e hederagenina) na motilida- } \\
\text { de intestinal de ratos }\end{array}$ & $\begin{array}{l}\text { Pré-clínico: Tiras do } \\
\text { estômago isolados de } \\
\text { ratos }\end{array}$ & $\begin{array}{l}\text { Foi observado efeito na motilidade } \\
\text { gástrica, possivelmente exercida pela } \\
\text { a-hederina }\end{array}$ \\
\hline
\end{tabular}

Turolla e Nascimento (2006) afirmaram que muitas plantas medicinais apresentam substâncias que podem desencadear reações adversas por seus próprios componentes, ou pela presença de contaminantes ou adulterantes em preparações fitoterápicas, o que aumenta a necessidade de um rigoroso controle de qualidade em todas as fases de fabricação, desde o cultivo até a elaboração do medicamento final (50).

A reação adversa a um medicamento é classificada como qualquer resposta que seja prejudicial, não intencional, e que ocorra nas doses normalmente utilizadas em seres humanos para profilaxia, diagnóstico e tratamento de doenças, ou para a modificação de uma função fisiológica (51). De acordo com dados registrados no Sistema Nacional de Informações Tóxico-Farmacológicas (52), entre os anos de 2010 a 2013 houve 4.424 casos de intoxicações no Brasil por plantas. O uso de plantas medicinais de forma errônea ou sem conhecimentos adequados, acaba levando grande parte da população à exposição e possíveis toxicidades. Um estudo de Herrera e Bruquera (2008) mostrou que são cada vez mais comuns os casos de hepatotoxicidade associada a produtos à base de plantas com propriedades atribuídas, principalmente, a redução de peso, variando desde hepatite simples, à hepatite fulminante, causando a morte ou necessidade de transplante de fígado (53).

Os fitoterápicos são, em geral, bem tolerados em estudos clínicos, geralmente sem efeitos colaterais em comparação com os grupos placebos, como com a Echinacea angustifolia (Equinácea) e Ginko biloba (Ginkgo), Hypericum perforatum L. (Erva de São João) e plantas medicinais chinesas (28). Mas algumas plantas apresentam toxicidade, como por exemplo, espécies do gênero Ephedra geram hipertensão, taquicardia, e derrames devido ao alcaloide efedrina, e espécies do gênero Aristolochia podem levar à toxicidade renal.

Em qualquer parte da planta pode haver substâncias tóxicas, podendo causar efeitos deletérios até mesmo pelo contato na pele, como irritações oculares, dermatites, alergias e queimaduras (54). 
Os estudos para avaliação da segurança deve incluir testes in vitro, ensaios de genotoxicidade in vivo, testes em animais para avaliação da carcinogenicidade contínua (três meses) ou intermitente (seis meses), estudos de toxicidade reprodutiva e de desenvolvimento, e efeitos sobre as enzimas que metabolizam medicamentos (49).

Dessa forma, a fiscalização e a obediência às instruções normativas devem ocorrer nas etapas de extração, processamento, conservação e armazenamento, para evitar possíveis contaminações microbianas e consequente perda das suas propriedades, e com isso, reduzir os riscos de pacientes ou consumidores desses produtos (55). Dados sobre a toxicidade pré-clínica de plantas medicinais ainda são pequenos, mas Turolla e Nascimento (2006) (analisaram estudos de dez espécies vegetais e observaram que de maneira geral, os experimentos em animais apresentaram baixa toxicidade aguda, subaguda e crônica e não mostraram atividades mutagênicas ou teratogênicas 50).

Dessa forma, pode ser observado que as plantas medicinais, de forma geral, possuem menor quantidade de efeitos colaterais e deletérios à saúde que a maioria dos fármacos convencionais. Porém, o uso de cada espécie, parte utilizada ou medicamento fitoterápico, em relação à prescrição, deve ser avaliado de forma específica e individual, levando em consideração a saúde do paciente, idade, patologias presentes, uso de medicamentos ou suplementos, entre outros, para dessa forma, garantir a melhora da saúde do paciente, sem colocá-lo em risco.

Marcadores Químicos evidenciados para alguns fitoterápicos selecionados. De acordo com Braga e cols. (2003), a pesquisa dos constituintes fitoquímicos presentes nas plantas é essencial para a validação de medicamentos fitoterápicos e englobam diversas etapas, como o isolamento e elucidação estrutural dos metabólitos secundários, que são importantes para identificar as espécies vegetais por meio de marcadores químicos, e no monitoramento das etapas de cultivo e produção de produtos (56). Por meio de testes analíticos como Cro- matografia Líquida de Alta Eficiência (CLAE) e Cromatografia em Camada Delgada (CCD) é possível autenticar a matéria prima vegetal, como se fosse a "impressão digital" da planta, importante não só para espécies utilizadas pela população e estudadas, mas também para medicamentos fitoterápicos de referência.

Além de estudos de adulterações e contaminações em fitoterápicos, é essencial também a realização de análise botânica e química minuciosa das plantas com uso terapêutico, em especial com plantas selvagens $(57,58)$. Newmaster e cols. (2013) avaliaram a autenticidade de mais de 40 produtos à base de plantas da América do Norte, com análise do DNA, e observaram que a grande maioria destes apresentou baixa qualidade, como substituição e contaminação (59). Isso interfere na efetividade dos medicamentos, o que leva à falta de confiança do consumidor em seu uso.

Dessa forma, o controle da qualidade é muito importante, e deve ser realizado por técnicas analíticas modernas, para assegurar a real composição dos metabólitos no preparo de fitoterápicos em grande escala; entre eles, vale ressaltar técnicas analíticas rápidas e o hifenamento da cromatografia à espectrometria de massas $(57,58)$.

As ferramentas analíticas modernas para controle da qualidade de medicamentos fitoterápicos são muito importantes, e essa garantia da qualidade requer intensa monitorização desde a coleta, até o produto final embalado. É de suma importância que os governos sigam as diretrizes da Organização Mundial da Saúde (OMS), e as monografias das espécies, para fortalecer o processo de regulamentação e reduzir a falta de qualidade dos produtos (60).

No Quadro 10 estão alguns exemplos de espécies vegetais registradas como medicamentos fitoterápicos com registro simplificado no Brasil em 2016, as partes utilizadas, dose diária, e o marcador específico ou padrão, utilizado para o controle da qualidade. 
Quadro 10. Marcadores específicos para algumas espécies em medicamentos fitoterápicos do Brasil (2016).

\begin{tabular}{|c|c|c|c|c|}
\hline Nome científico & Nome popular & Parte utilizada & Padronização/ Marcador & Dose diária \\
\hline Aesculus hippocastanum L. & Castanha da Índia & Sementes & $\begin{array}{l}\text { Glicosídeos triterpênicos } \\
\text { expressos em escina anidra }\end{array}$ & $\begin{array}{l}32 \text { a } 120 \mathrm{mg} \text { de glicosídeos } \\
\text { triterpênicos expressos em esci- } \\
\text { na anidra }\end{array}$ \\
\hline Allium sativum $\mathrm{L}$. & Alho & Bulbo & Alicina & 3 a $5 \mathrm{mg}$ de alicina \\
\hline Cynara scolymus L. & Alcachofra & Folhas & $\begin{array}{l}\text { Derivados de ácido cafeoil- } \\
\text { quínico expressos em ácido } \\
\text { clorogênico }\end{array}$ & $\begin{array}{l}24 \text { a } 48 \mathrm{mg} \text { de derivados de } \\
\text { ácido cafeoilquínico expressos } \\
\text { em ácido clorogênico }\end{array}$ \\
\hline Ginkgo biloba L. & Ginkgo & Folhas & $\begin{array}{l}\text { Ginkgoflavonóides ( } 22 \% \text { a } \\
27 \% \text { ) expressos em querce- } \\
\text { tina, kaempferol e isorham- } \\
\text { netina; e terpenolactonas } \\
\text { ( } 5 \% \text { a } 7 \% \text { ) expressos em } \\
\text { ginkgolídeos A, B, C e bilo- } \\
\text { balídeo }\end{array}$ & $\begin{array}{l}26,4 \text { a } 64,8 \text { mg de ginkgoflavo- } \\
\text { nóides e } 6 \text { a } 16,8 \text { mg de terpe- } \\
\text { nolactonas }\end{array}$ \\
\hline Glycine max (L.) Merr & Soja & Sementes & Isoflavonas & 50 a $120 \mathrm{mg}$ de isoflavonas \\
\hline Mentha $x$ piperita $\mathrm{L}$. & Hortelã-pimenta & Folhas & $\begin{array}{l}35 \% \text { a } 55 \% \text { de mentol e } \\
14 \% \text { a } 32 \% \text { de mentona }\end{array}$ & $\begin{array}{l}60 \text { a } 440 \mathrm{mg} \text { de mentol e } 28 \text { a } \\
256 \mathrm{mg} \text { de mentona }\end{array}$ \\
\hline Panax ginseng C. A. Mey. & Ginseng & Raiz & $\begin{array}{l}\text { Ginsenosídeos Rg1, Re, Rb1, } \\
\text { Rc, Rb2, Rd, Rf e Rg2 (Rf e } \\
\text { Rg2 apenas para identifi- } \\
\text { cação) }\end{array}$ & $\begin{array}{l}8 \text { a } 16 \text { mg de ginsenosídeos Rg1, } \\
\text { Re, Rb1, Rc, Rb2 e Rd }\end{array}$ \\
\hline Paullinia cupana Kunt & Guaraná & Sementes & $\begin{array}{l}\text { Metilxantinas expressas em } \\
\text { cafeína }\end{array}$ & $\begin{array}{l}15 \text { a } 70 \text { mg de metilxantinas } \\
\text { expressas em cafeína }\end{array}$ \\
\hline Matricaria recutita $\mathrm{L}$. & Camomila & Capítulos florais & $\begin{array}{l}\text { Apigenina-7-glicosídeo e } \\
\text { derivados bisabolônicos } \\
\text { calculados como levomenol }\end{array}$ & $\begin{array}{l}4 \text { a } 24 \text { mg de apigenina-7- gli- } \\
\text { cosídeo }\end{array}$ \\
\hline $\begin{array}{l}\text { Mikania glomerata Spreng., M. } \\
\text { laevigata Sch. Bip. ex Baker }\end{array}$ & Guaco & Folhas & Cumarina & 0,5 a $5 \mathrm{mg}$ de cumarina \\
\hline Peumus boldus Molina & $\begin{array}{l}\text { Boldo, Boldo-do- } \\
\text { Chile }\end{array}$ & Folhas & $\begin{array}{l}\text { Alcaloides totais expressos } \\
\text { em boldina }\end{array}$ & $\begin{array}{l}2 \text { a } 5 \mathrm{mg} \text { alcaloides totais ex- } \\
\text { pressos em boldina }\end{array}$ \\
\hline Passiflora edulis Sims & $\begin{array}{l}\text { Maracujá, Passi- } \\
\text { flora }\end{array}$ & Partes aéreas & $\begin{array}{l}\text { Flavonoides totais expressos } \\
\text { em vitexina }\end{array}$ & $\begin{array}{l}30 \text { a } 120 \mathrm{mg} \text { de flavonoides } \\
\text { totais expressos em vitexina }\end{array}$ \\
\hline Melissa officinalis L. & $\begin{array}{l}\text { Melissa, Erva-ci- } \\
\text { dreira }\end{array}$ & Folhas & $\begin{array}{l}\text { Ácidos hidroxicinâmicos } \\
\text { expressos em ácido } \\
\text { rosmarínico }\end{array}$ & $\begin{array}{l}60 \text { a } 180 \text { mg de ácidos hidroxi- } \\
\text { cinâmicos expressos em ácido } \\
\text { rosmarínico }\end{array}$ \\
\hline Pimpinella anisum $\mathrm{L}$. & Erva-doce, Anis & Frutos & Trans-anetol & $\begin{array}{l}0 \text { a } 1 \text { ano: } 16 \text { a } 45 \mathrm{mg} \text { de trans- } \\
\text {-anetol; } 1 \text { a } 4 \text { anos: } 32 \text { a } 90 \mathrm{mg} \\
\text { de trans-anetol; adultos: } 80 \mathrm{a} \\
225 \mathrm{mg} \text { de trans-anetol }\end{array}$ \\
\hline
\end{tabular}

Adaptado de BRASIL (62).

Os medicamentos fitoterápicos podem ser simples (uma única espécie vegetal), ou compostos (duas ou mais espécies). Também é necessário que contenha na descrição do medicamento fitoterápico, a concentração real em peso ou volume da matéria prima, correspondente ao marcador, ou princípio ativo quando este for conhecido (61). Nos processos de registro/renovação de fitoterápicos, é necessário que o laboratório apresente um marcador exclusivo para cada planta ou apresente outro método, validado, de controle da qualidade (62). O marcador é um componente ou classe de compostos, como por exemplo, flavonoides ou alcaloides, que estão presentes e são rela- cionados aos efeitos farmacológicos, sendo usado como referência para o controle de qualidade tanto da matéria prima vegetal como de fitoterápicos (63).

O princípio ativo do fitoterápico pode ser uma substância ou classes de compostos, quimicamente caracterizada, possui ação conhecida e responsável pela atividade farmacológica de forma parcial ou total, dos efeitos terapêuticos do medicamento fitoterápico (63).

Pereira (2011) observou que dos estudos clínicos de medicamentos fitoterápicos avaliados, apenas $27,8 \%$ descreveram a padronização relacionada à determinada 
substância marcadora, e não mais do que 2,8\% relataram pelo menos um teste de controle de qualidade para os produtos utilizados (61).

Quando se trata de um medicamento fitoterápico composto, não é aceito o doseamento de apenas uma substância; dessa forma, é necessário utilizar um marcador específico, para cada espécie presente na formulação, pois o efeito terapêutico nesse caso, não é devido a apenas um componente, e sim de um fitocomplexo (62).

$\mathrm{O}$ estabelecimento de marcadores químicos para cada espécie é difícil, bem como há dificuldade da elaboração de monografias farmacopeicas para essas espécies de plantas (61).

\section{CONCLUSÃO}

A prática do uso de plantas medicinais é antiga, e possui grande valor e utilização por parte da po- pulação. A biodiversidade encontrada nos países do Mercosul é muito grande e o Brasil é considerado o país mais biodiverso do mundo, com cerca de $1 / 3 \mathrm{da}$ flora mundial.

Todas as espécies do presente estudo apresentaram promissor potencial terapêutico, porém a dulcamara e aloe podem ser consideradas possivelmente tóxicas. É importante salientar que as espécies com maior número de estudos encontrados na literatura foram Alcachofra e aloe.

Vale ressaltar que de forma geral são escassos os estudos básicos sobre as plantas medicinais, que tenham como objetivo a comprovação de seus efeitos, estudos de dose-efeito, ensaios clínicos, toxicidade, entre outros, que são necessários para o desenvolvimento de produtos fitoterápicos e para que o profissional de saúde tenha segurança na prescrição das mesmas.

\section{REFERÊNCIAS}

1. Marston A, Hostettmann K. Natural product analysis over the last decades. Planta Med. 2009; 75:672-682. DOI: $10.1055 / \mathrm{s}-0029-1185379$.

2. BRASIL. Ministério do Meio Ambiente. Biodiversidade Brasileira. 2016. Available in: < http://www.mma.gov.br/ biodiversidade/biodiversidade-brasileira>. [cited in 2017 fev. 07]

3. Cragg GM, Newman DJ. Biodiversidade: medicamentos ao longo de milênios. In: Yunes RA, Cechinel-Filho V. Química de Produtos Naturais: novos fármacos e a moderna farmacognosia. 4 ed. Itajaí: Editora Univali, 2014, p. 58-84.

4. Bolzani VS, Flausino-Júnior O, Valli M. Biodiversidade Brasileira: uma fonte potencial de agentes terapêuticos ainda inexplorada. In: Yunes, R.A.; Cechinel-Filho, V. Química de Produtos Naturais: novos fármacos e a moderna farmacognosia. 4 ed. Itajaí: Editora Univali, 2014, p. 397-429.

5. Cechinel-Filho V. Medicamentos de origem vegetal: atualidades, desafios, perspectivas. Itajaí: Editora Univali. 2015.

6. Silva RM, Santos IM, Kawakita RF, Silva $M G$. Enfermagem e plantas medicinais: uso de fitoterápicos como prática terapêutica. Encontro Regional Centro-Oeste 2014. Available in: http://conferencia2016.redeunida.org.br/ ocs/index.php/regionais/centro-oeste/paper/view/240. [cited in 2015 july 21]

7. Hossain MA, Kalbani MSAA, Al Farsi SBJ, Welli AM, Al-Riyami Q. Comparative study of total phenolics, fla- vonoids contents and evaluation of antioxidant and antimicrobial activities of different polarities fruits crude extracts of Datura metel L. APJTD. 2014;4(5):378-383. DOI: 10.1016/S2222-1808(14)60591-0.

8. Kuppusamy P, Yusoff MM, Parine NR, Govindan N. Evaluation of in-vitro antioxidant and antibacterial properties of Commelina nudiflora L. extracts prepared by different polar solvents. Saudi J Biol Sci. 2015;22:293301. DOI: 10.1016/j.sjbs.2014.09.016.

9. Xu DP, Li Y, Meng X, Zhou T, Zhou Y, Zheng J, Zhang JJ, Li HB. Natural antioxidants in foods and medicinal plants: extraction, assessment and resources. Int $\mathrm{J}$ Mol Sci. 2017;18(1):1-32. DOI: 10.3390/ijms18010096.

10. Cechinel-Zanchett CC. Legislação e controle de qualidade de medicamentos fitoterápicos nos países do Mercosul. Infarma. 2016;28(3):123-139. DOI: 10.14450/23189312.v28.e3.a2016.pp123-139.

11. Fulanetti FB, Camargo GGR, Randazzo-Moura P. Toxic effects of the administration ofMikania glomerata Sprengel during the gestational period of hypertensive rats. Open Vet J. 2016;6(1):23-29.

12. Felipe MBMC, Carvalho FM, Félix-Silva J, Fernandes-Pedrosa MF, Scortecci KC, Agnez-Lima SR, Batiztuzzo de Medeiros SR. Evaluation of genotoxic and antioxidant activity of an Aesculus hippocastanum L. (Sapindaceae) phytotherapeutic agent. Biomed Prev Nutr. 2013;3(1):261-266. DOI: 10.1016/j.bionut.2012.10.014.

13. Küçükkurt I, Ince S, Keleş H, Akkol EK, Avci G, Yeşilada E, Bacak E. Beneficial effects of Aesculus hippocastanum 
L. seed extract on the body's own antioxidant defense system on subacute administration. J Ethnopharmacol. 2010;129(1):18-22. DOI: 10.1016/j.jep.2010.02.017.

14. Brito MAS, Bueno AJA, Rodrigues JS, Sousa SA, Fernandes CKC. Avaliação da qualidade de cápsulas de castanha da Índia (Aesculus hippocastanum L.). Rev Eletronica FMB. 2014; 7(1):1-9.

15. Santana LCLR, Brito MRM, Oliveira GLS, Citó AMGL, Alves CQ, David JP, David JM, Freitas RM. Mikania glomerata: Phytochemical, Pharmacological, and Neurochemical Study. Evid-Based Compl Alt. 2014;2014:1-11. DOI: $10.1155 / 2014 / 710410$.

16. Soares LSS, et al. Preparation of dry extract of Mikania glomerata Sprengel (Guaco) and determination of its coumarin levels by spectrophotometry and HPLC-UV. Molecules. 2012;17(9):10344-10354. DOI: 10.3390/molecules 170910344 .

17. Czelusniak KE, Brocco A, Pereira DF, Freitas GLB. Farmacobotânica, fitoquímica e farmacologia do Guaco: revisão considerando Mikania glomerata Sprengel e Mikania laevigata Schulyz Bip. ex Baker. Rev. Bras. Plantas med. 2012;14(2):400-409. DOI: 10.1590/S151605722012000200022 .

18. Noldin VF, Cechinel-Filho V, Delle-Monache F, Benassi JC, Christmann IL, Pedrosa RC, Yunes RA. Chemical composition and biological activities of the leaves of $C y$ nara scolymus L. (artichoke) cultivated in Brazil. Quím. Nova. 2003;26(3): 331-334. DOI: 10.1590/S010040422003000300008.

19. Plantamed. Cynara scolymus L. - ALCACHOFRA. 2015. Available in: http://www.plantamed.com.br/plantaservas/especies/Cynara_scolymus.ht. [cited in 2015 aug 18]

20. Rondanelli M, Monteferrario F, Perna S, Faliva MA, Opizzi A. Health-promoting properties of artichoke in preventing cardiovascular disease by its lipidic and glycemic-reducing action. Monaldi Arch Chest Dis. 2013;80(1):17-26. DOI: 10.4081./monaldi.2013.87.

21. Mattos MIS. Avaliação dos potenciais efeitos de toxicidade sub-aguda, teratogenicidade e imunotoxicidade da Cynara scolymus (alcachofra): estudo em ratos. 124 p. [Tese], Faculdade de Medicina Veterinária e Zootecnia, Universidade Federal de São Paulo - USP, São Paulo. 2014.

22. El Senousy AS, Farag MA, Al-Mahdy DA, Wessjohann LA. Developmental changes in leaf phenolics composition from three artichoke cvs. (Cynara scolymus) as determined via UHPLC-MS and chemometrics. Phytochemistry. 2014;108:67-76. DOI: 10.1016/j.phytochem.2014.09.004.

23. Aspen Pharma. Bula Alcachofra. Available in: http:// www.aspenpharma.com.br/site/arq/Alcachofra.pdf. [cited in 2015 aug. 14].

24. Kulza M, Adamska K, Seńczuk-Przybyłowska M, Woźniak A, Wachowiak A, Miechowicz I, Horoszkiewicz M,
Nowak G, Florek E. Artichoke--herbal drug. Przegl Lek. 2012;69(10):1122-1126.

25. Botsaris AS, Alves LF. Cynara scolymus L. (Alcachofra). Rev Fitos. 2007;3(3):51-63.

26. Heidarian E, Rafieian-Kopaei M. Protective effect of artichoke (Cynara scolymus) leaf extract against lead toxicity in rat. Pharm. Biol. 2013;51(9):1104-1109. DOI: 10.3109/13880209.2013.777931.

27. Horoszkiewicz M, Kulza M, Malinowska K, Woźniak A, Seńczuk-Przybyłowska M, Wachowiak A, Florek E. Artichoke--untapped potential of herbal medicine in the treatment of atherosclerosis and liver diseases. Przegl Lek. 2012;69(10):1129-1131.

28. Ramzan I (Ed.) Phytotherapies: Efficacy, Safety, and Regulation. Wiley. 2015.

29. Magielse J, Verlaet A, Breynaert A, Keenoy BM, Apers $\mathrm{S}$, Pieters L, Hermans N. Investigation of the in vivo antioxidative activity of Cynara scolymus (artichoke) leaf extract in the streptozotocin-induced diabetic rat. Mol Nutr Food Res. 2014;58:211-215. DOI: 10.1002/ mnfr.201300282.

30. Plantamed. Solanum dulcamara L. - DULCAMARA. Available in: http://www.plantamed.com.br/plantaservas/especies/Solanum_dulcamara.htm. [cited in 2016 apr. 18]

31. Visser EJ, Zhang Q, De Gruyter F, Martens S, Huber H.Shade affects responses to drought and flooding - acclimation to multiple stresses in bittersweet (Solanum dulcamara L.). Plant Biol. 2016;18(1):112-119. DOI: 10.1111/plb.12304.

32. Vogel H, González B, Razmilic I. Boldo (Peumus boldus) cultivated under different light conditions, soil humidity and plantation density. Ind Crops Prod. 2011;34(2):13101312. DOI: $10.1016 /$ j.indcrop.2010.10.039.

33. Falé PL, Amaral F, Amorim Madeira PJ, Sousa Silva M, Florêncio MH, Frazão FN, Serralheiro ML. Acetylcholinesterase inhibition, antioxidant activity and toxicity of Peumus boldus water extracts on HeLa and CACO-2 cell lines. Food Chem Toxicol. 2012;50(8):2656-2662. DOI: 10.1016/j.fct.2012.04.049.

34. Klimaczewski CV, Saraiva RA, Roos DH, Boligon A, Athayde ML, Kamdem JP, Barbosa NV, Rocha, JBT. Antioxidant activity of Peumus boldus extract and alkaloid boldine against damage induced by $\mathrm{Fe}(\mathrm{II})$-citrate in rat liver mitochondria in vitro. Ind Crops Prod. 2014;54:240-247. DOI: 10.1016/j.indcrop.2013.11.051

35. Asadi-Samani M, Bahmani M, Rafieian-Kopaei M. The chemical composition, botanical characteristic and biological activities of Borago officinalis: a review. APJTD 2014;7(1):22-28. DOI: 10.1016/ S1995-7645(14)60199-1.

36. Farhadi R, Balashahri, MS, Tilebeni HG, Sadeghi M. Pharmacology of borage (Borago officinalis L.) medicinal plant. Int J Agron Plant Prod. 2012;3(2):73-77. 
37. Ghahremanitamadon F, Shahidi S, Zargooshnia S, Nikkhah A, Ranjbar A, Asl SS. Protective effects of Borago officinalis extract on amyloid $\beta$-peptide(25-35)-induced memory impairment in male rats: a behavioral study. BioMed Res Int. 2014;1-8. DOI: 10.1155/2014/798535

38. Miroddi M, Navarra M, Calapai F, Mancari F, Giofrè SV, Gangemi S, Calapai G. Review of clinical pharmacology of Aloe vera L. in the treatment of psoriasis. Phytother Res. 2015; 29(5):648-655. DOI: 10.1002/ ptr.5316.

39. Guo X, Mei N. Aloe vera - A review of toxicity and adverse clinical effects. J Environ Sci Health C Environ Carcinog Ecotoxicol Rev. 2016;34(2):77-96. DOI: 10.1080/10590501.2016.1166826.

40. Sudarshan R, Annigeri RG, Vilayabala GS. Aloe vera in the treatment for oral submucous fibrosis - a preliminary study. J Oral Pathol Med. 2012;41(10):755-761. DOI: 10.1111/j.1600-0714.2012.01168.x.

41. BRASIL. Agência Nacional de Vigilância Sanitária Anvisa. Informe Técnico $n^{\circ} .47$, de 16 de novembro de 2011. Available in: http://portal.anvisa.gov.br/wps/wcm/ connect/c66ea5804924c8f49d829f14d16287af/Informe Tecnico_n_47_de_16_de_novembro_de_2011.pdf?MO$\mathrm{D}=\mathrm{AJPERES}$. [cited in 2016 may 01]

42. Cazarin CB, et al. Passiflora edulis peel intake and ulcerative colitis: approaches for prevention and treatment. Exp Biol Med. 2014;239(5):542-551. DOI: $10.1177 / 1535370214525306$.

43. Otify A, George C, Elsayed A, Farag MA. Mechanistic evidence of Passiflora edulis (Passifloraceae) anxiolytic activity in relation to its metabolite fingerprint as revealed via LC-MS and chemometrics. Food Funct. 2015;6(12):3807-3817. DOI: 10.1039/c5fo00875a.

44. Devaki K, Beulah U, Akila G, Gopalakrishnan VK. Effect of aqueous extract of Passiflora edulis on biochemical and hematological parameters of Wistar Albino rats. Toxicol Int. 2012;19(1):63-67. DOI: 10.4103/09716580.94508 .

45. Silva JK et al. Antioxidant activity of aqueous extract of passion fruit (Passiflora edulis) leaves: In vitro and in vivo study. Food Res Int. 2013;53(2):882-890. DOI: 10.1016/j.foodres.2012.12.043

46. Anuradha R. The antiinflammatory and antiarthritic properties of ethanol extract of Hedera helix. Indian J. Pharm. Sci. 2013;75(1):99-102. DOI: 10.4103/0250474X.113537.

47. Uddin G, Rauf A, Qaisar M, Rehman TJ, Latif A, Ali M. Preliminary phytochemical screening and antimicrobial activity of Hedera helix L. MEJSR. 2011;8(1):198-202.

48. Mendel M, Chłopecka M, Dziekan N, Wiechetek M. The effect of the whole extract of common ivy (Hedera helix) leaves and selected active substances on the motoric activity of rat isolated stomach strips. J Ethnopharmacol. 2011;134(3):796-802. DOI: 10.1016/j.jep.2011.01.036.
49. Gromek K, Drumond N, Simas P. Pharmacovigilance of herbal medicines. Int J Risk Saf Med. 2015;27(2):55-65. DOI: $10.3233 /$ JRS-150643.

50. Turolla MSR, Nascimento ES. Informações toxicológicas de alguns fitoterápicos utilizados no Brasil. Rev. Bras. Ciênc. Farm. 2006;42(2):289-306. DOI: 10.1590/ S1516-93322006000200015.

51. BRASIL. Ministério da Saúde. Agência Nacional de Vigilância Sanitária - Anvisa. Resolução $n^{\circ} 140$ de 29/05/2003. Available in: <http://www.cff.org.br/userfiles/file/resolucao_sanitaria/140.pdf $>$. [cited in $2017 \mathrm{fev}$. 16]

52. SINITOX. Sistema Nacional de Informações Tóxico-Farmacológicas. Dados Nacionais. Available in: <http:// sinitox.icict.fiocruz.br/dados-nacionais $>$. [cited in 2017 july 24]

53. Herrera S, Bruquera M. Hepatotoxicity induced by herbs and medicines used to induce weight loss. Gastroenterol Hepatol. 2008;31(7):447-453.

54. Fitoterapia. Plantas Tóxicas. Available in: http://www. fitoterapia.com.br/portal/index.php?option=com_content\&task=view\&id $=68$. [cited in 2015 oct 28]

55. Souza FS, Maciel CCS. Produtos fitoterápicos e a necessidade de um controle de qualidade microbiológico. Rev. Eletrônica de Ciências. 2010;3(2):22-30.

56. Braga FC, Valadares YM, Costa MA, Lombardi JÁ, Oliveira AB. Estudo fitoquímico de Erythraea centaurium, Jacaranda caroba, Remijia ferruginea e Solanum paniculatum visando identificar marcadores químicos para o fitoterápico Ierobina ${ }^{\circledR}$. Rev Bras Farmacog. 2003;13(2):28-31. DOI: http://dx.doi.org/10.1590/ S0102-695X2003000400010.

57. Gobbo-Neto L, Lopes NP. Plantas medicinais: fatores de influência no conteúdo de metabólitos secundários. Quím. Nova. 2007;30(2):374-381.

58. Gouvea DR, Pavarini DP, Carollo CA, Lopes NP. Variações do metabolismo secundário vegetal: exemplos com plantas nativas do Brasil. In: Yunes RA, Cechinel-Filho V. Química de Produtos Naturais: novos fármacos e a moderna farmacognosia. 6 ed. Itajaí: Editora Univali. 2016, p. 399-420.

59. Newmaster SG. DNA barcoding detects contamination and substitution in North American herbal products. BMC Medicine. 2013;11(1). DOI: 10.1186/1741-701511-222.

60. Kunle OF, Egarevba HO, Ahmadu PO. Standardization of herbal medicines - A review. IJBC. 2012;4(3):101112. DOI: $10.5897 / \mathrm{IJBC} 11.163$.

61. Pereira SSTC. Medicamentos fitoterápicos e drogas vegetais industrializados e oficializados pelo Ministério da Saúde no Brasil: regulamentação sanitária, abrangência e qualidade dos estudos pré-clínicos e clínicos. 344 p. Tese, Escola Nacional de Saúde Pública Sergio Arouca, Fundação Oswaldo Cruz, Rio de Janeiro. 2013. 
62. BRASIL. Ministério da Saúde. Agência Nacional de Vigilância Sanitária - Anvisa. Posicionamentos da Câmera Técnica da Fitoterápicos (CATEF) quanto ao registro de Medicamentos Fitoterápicos 2007. Available in: http:// www.anvisa.gov.br/medicamentos/catef/posicionamento_registro_fitoterapicos.pdf $>$. [cited in 2016 may 01]

63. BRASIL. Ministério da Saúde. Agência Nacional de Vigilância Sanitária - Anvisa. Instrução Normativa n ${ }^{\circ} 02$ de 13 de maio de 2014. Available in: http://bvsms.saude.gov. br/bvs/saudelegis/anvisa/2014/int0002_13_05_2014. pdf. [cited in 2016 apr. 24]a

64. Jiang N, Xin W, Wang T, Zhang L, Fan H, Du Y, Li C, $\mathrm{Fu}$ F. Protective effect of aescin from the seeds of Aesculus hippocastanum on liver injury induced by endotoxin in mice. Phytomedicine. 2011;18(14):1276-1286. DOI: 10.1016/j.phymed.2011.06.011.

65. Avci G, Küçükkurt I, Küpeli AE, Yesilada E. Effects of escin mixture from the seeds of Aesculus hippocastanum on obesity in mice fed a high fat diet. Pharm. Biol. 2010;48(3):247-252. DOI: $10.3109 / 13880200903085466$.

66. Xin W, Zhang L, Sun F, Jiang N, Fan H, Wang T, Li Z, He $\mathrm{J}, \mathrm{Fu}$ F. Escin exerts synergistic anti-inflammatory effects with low doses of glucocorticoids in vivo and in vitro. Phytomedicine. 2011;18(4):272-277. DOI: 10.1016/j. phymed.2010.08.013.

67. Kimura H, Ogawa S, Sugiyama A, Jisaka M, Takeuchi T, Yokota K. Anti-obesity effects of highly polymeric proanthocyanidins from seed shells of Japanese horse chestnut (Aesculus turbinate Blume). IFRJ. 2011;44(1):121-126. DOI: 10.1016/j.foodres.2010.10.052.

68. Mourão VB, Guraldi GM, Neves LMG, Gaspi RAF, Alves AA, Esquisatto MAM, Mazzi MV, Mendonça FAS, Santos GMT. Anti-hemorrhagic effect of hydro-alcoholic extract of the leaves of Mikania glomerata in lesions induced by Bothrops jararaca venom in rats. Acta Cirur Bras. 2014;29(1):30-37. DOI: 10.1590/S010286502014000100005 .

69. Barbosa LC, Dias de Morais M, Paula CA, Silva Ferreira MC, Jordão AA, Andrade e Silva ML, Kanupp Bastos J, Silva-Filho AA, Oliveira Cecchi A. Mikania glomerata Sprengel (Asteraceae) influences the mutagenicity induced by doxorubicin without altering liver lipid peroxidation or antioxidant levels. J Toxicol Environ Health. 2012; 75(16-17):1102-1107. DOI: 10.1080/15287394.2012.697842.

70. Floriano RS, Nogueira RM, Sakate M, Laposy CB, Motta YP, Sangiorgio F, David HC, Nabas JM. Effect of Mikania glomerate (Asteraceae) leaf extract combined with anti-venom serum on experimental Crotalus $d u$ rissus (Squamata: Viperidae) envenomation in rats. Rev Biol Trop. 2009;57(4):929-937.

71. Freitas TP, Silveira PC, Rocha LG, Rezin GT, Rocha J, Citadini-Zanette V, Romão PT, Dal-Pizzol F, Pinho RA, Andrade VM, Streck EL. Effects of Mikania glomera- te Spreng. And Mikania laevigata Schultz Bip. ex Baker (Asteraceae) extracts on pulmonary inflammation and oxidative stress caused by acute coal dust exposure. J Med Food. 2008;11(4):761-766. DOI: 10.1089/ jmf.2008.0051.

72. Costa RJ, Diniz A, Mantovani MS, Jordão BQ. In vitro study of mutagenic potential of Bidens pilosa Linne and Mikania glomerata Sprengel using the comet and micronucleus assays. J Ethnopharmacol. 2008;118:86-93. DOI: 10.1016/j.jep.2008.03.014.

73. Colak E, Ustuner MC, Tekin N, Colak E, Burukoglu D, Degirmenci I, Gunes HV. The hepatocurative effects of Cynara scolymus L. leaf extract on carbon tetrachloride-induced oxidative stress and hepatic injury in rats. Springerplus. 2016; 5(216). DOI: 10.1186/s40064-016-1894-1.

74. Mustafa HN, Awdan SAE, Hegazy GA, Jaleel GAA. Prophylactic role of coenzyme Q10 and Cynara scolymus $\mathrm{L}$ on doxorubicin-induced toxicity in rats: biochemical and immunohistochemical study. Indian $\mathrm{J}$ Pharmacol. 2015;47(6):649-656. DOI: 10.4103/0253-7613.169588.

75. Mileo AM, Di Venere D, Abbruzzese C, Miccadei S. Long term exposure to polyphenols of artichoke $(C y$ nara scolymus 1.) exerts induction of senescence driven growth arrest in the mda-mb231 human breast cancer cell line. Oxid Med Cell Longev. 2015;2015:1-12. DOI: $10.1155 / 2015 / 363827$.

76. Pulito C, et al. Cynara scolymus affects malignant pleural mesothelioma by promoting apoptosis and restraining invasion. Oncotarget. 2015;6(20):8134-18150. DOI: 10.18632/ oncotarget.4017.

77. El-Morsy EME, Kamel R. Protective effect of artichoke leaf extract against paracetamol-induced hepatotoxicity in rats. Pharm Biol. 2015; 53(2):167-173. DOI: 10.3109/13880209.2014.913066.

78. Sharma A. Antibacterial activity of ethanolic extracts of some arid zone plants. IJPR. 2011;3(1):283-286.

79. Rajashekhar U, Vrushabendra BMS, Jayaveera K. Hepatoprotective activity of hydro-alcoholic extract of whole plant of Solanum dulcamara L. and Nephrolepis cordifolia (L) C. presl against paracetamol induce hepatotoxicity in albino rats. AJPCR. 2015;8(2):364-370.

80. Mutlu E, Yildirim AB, Turker AU. In vitro micropropagation, antibacterial and antitumor activity of bittersweet (Solanum dulcamara L.). N Biotechnol. 2012;9(2326):174-175. DOI: 10.1016/j.nbt.2012.08.486.

81. Santos CZ, Bobek VB, Pietruchinsk E. Avaliação da atividade antifúngica do óleo essencial de Peumus boldus (Monimiaceae) frente à levedura da espécie Candida albicans. Visão Acadêmica. 2014;15(2):1518-8361.

82. Mondal J, Bishayee K, Panigrahi AK, Khuda-Bukhsh AR. Low doses of ethanolic extract of Boldo (Peumus boldus) can ameliorate toxicity generated by cisplatin in normal liver cells of mice in vivo and in WRL-68 cells in vitro, but not in cancer cells in vivo or in vitro. J Integr Med. 2014;12(5):425-438. DOI: $10.1016 / \mathrm{S} 2095$ 4964(14)60045-5. 
83. Pastene E, Parada V, Avello M, Ruiz A, García A. Catechin-based procyanidins from Peumus boldus Mol. aqueous extract inhibit Helicobacter pylori urease and adherence to adenocarcinoma gastric cells. Phytother Res. 2014;28(11):1637-1645. DOI: 10.1002/ptr.5176.

84. Shahraki MR, Ahmadimoghadm M, Shahraki AR. The antinociceptive effects of hydroalcoholic extract of $\mathrm{Bo}$ rago Officinalis flower in male rats using formalin test. Basic Clin Neurosci. 2015; 6(4):285-290.

85. Zargooshnia S, Shahidi S, Ghahremanitamadon F, Nikkhah A, Mehdizadeh M, Soleimani Asl S. A.The protective effect of Borago officinalis extract on amyloid $\beta$ (25-35)-induced long term potentiation disruption in the dentate gyrus of male rats. Metab Brain Dis. 2015;30(1):151-156. DOI: 10.1007/s11011-014-9594-4.

86. Arm JP et al. Impact of botanical oils on polyunsaturated fatty acid metabolism and leukotriene generation in mild asthmatics. Lipids Health Dis. 2013;2(12):141, 2013. DOI: $10.1186 / 1476-511 X-12-141$.

87. Tso P, Caldwell J, Lee D, Boivin GP, DeMichele SJ. Comparison of growth, serum biochemistries and $n-6$ fatty acid metabolism in rats fed diets supplemented with high-gamma-linolenic acid safflower oil or borage oil for 90 days. Food Chem Toxicol. 2012;50(6):1911-1919. DOI: 10.1016/j.fct.2012.01.001.

88. Wauquier F, et al. Borage and fish oils lifelong supplementation decreases inflammation and improves bone health in a murine model of senile osteoporosis. Bone. 2012;50(2):553-561. DOI: 10.1016/j.bone.2011.05.030.

89. Baradaran A, Nasri H, Nematbakhsh M, Rafieian-Kopaei M. Antioxidant activity and preventive effect of aqueous leaf extract of Aloe vera on gentamicin-induced nephrotoxicity in male Wistar rats. Clin Ther. 2014;165(1):7-11. DOI: 10.7471/CT.2014.1653.

90. Huseini HF, Kianbakht S, Hajiaghaee R, Dabaghian FH. Anti-hyperglycemic and anti-hypercholesterolemic effects of Aloe vera leaf gel in hyperlipidemic type 2 diabetic patients: a randomized double-blind placebo controlled clinical trial. Planta Medica. 2012;78(4):311-316. DOI: $10.1055 / \mathrm{s}-0031-1280474$.

91. Dinesh D, Murugan K, Madhiyazhagan P, Panneerselvam C, Kumar PM, Nicoletti M, Jiang W, Benelli G, Chandramohan B, Suresh U. Mosquitocidal and antibacterial activity of green-synthesized silver nanoparticles from Aloe vera extracts: towards an effective tool against the malaria vector Anopheles stephensi I. Parasitol Res. 2015;114(4):1519-1529. DOI: 10.1007/s00436-0154336-z.

92. Vijayalakshmi D, Dhandapani R, Jayaveni S, Jithendra PS, Rose C, Mandal AB. In vitro antiinflammatory activity of Aloe vera by down regulation of MMP-9 in peripheral blood mononuclear cells. J Ethnopharmacol. 2012;141(1):542-546. DOI: 10.1016/j.jep.2012.02.040.

93. Rezazadeh F, Moshaverinia M, Motamedifar M, Alyaseri M. Assessment of anti HSV-1 activity of Aloe vera gel extract: an in vitro study. J Dent. (Shiraz.). 2016;17(1):4954.
94. Werawatganon D, Rakananurak N, Sallapant S, Prueksapanich P, Somanawat K, Klaikeaw N, Rerknimitr R. Aloe vera attenuated gastric injury on indomethacin-induced gastropathy in rats. World J Gastroenterol. 2014;20(48):18330-18337. DOI: 10.3748/ wjg.v20.i48.18330.

95. Guven M, Gölge UH, Aslan E, Sehitoglu MH, Aras AB, Akman T, Cosar M. The effect of aloe vera on ischemia-Reperfusion injury of sciatic nerve in rats. Biomed Pharmacother. 2016;79:201-207. DOI: 10.1016/j.biopha.2016.02.023.

96. Sahebjamee M, Mansourian A, Hajimirzamohammad M, Zadeh MT, Bekhradi R, Kazemian A, Manifar S, Ashnagar S, Doroudgar K. Comparative efficacy of Aloe vera and benzydamine mouthwashes on radiation-induced oral mucositis: a triple-blind, randomised, controlled clinical trial. Oral Health Prev Dent. 2015;13(4):309-315. DOI: 10.3290/j.ohpd.a33091.

97. Klein N, Gazola AC, Lima TC, Schenkel E, Nieber $\mathrm{K}$, Butterweck V. Assessment of sedative effects of Passiflora edulis f. flavicarpa and Passiflora alata extracts in mice, measured by telemetry. Phytother Res. 2014;28(5):706-713. DOI: 10.1002/ptr.5043.

98. Dzotam JK, Touani FK, Kuete V. Antibacterial and antibiotic-modifying activities of three food plants (Xanthosoma mafaffa Lam., Moringa oleifera (L.) Schott and Passiflora edulis Sims) against multidrug-resistant (MDR) Gram-negative bacteria. BMC Complement Altern Med. 2016;16(1). DOI: 10.1186/s12906-016-09907.

99. Kandandapani S, Balaraman AK, Ahamed HN. Extracts of passion fruit peel and seed of Passiflora edulis (Passifloraceae) attenuate oxidative stress in diabetic rats. Chin J Nat Med. 2015;13(9):680-686. DOI: 10.1016/S18755364(15)30066-2.

100. Corrêa EM, et al. The intake of fiber mesocarp passionfruit (Passiflora edulis) lowers levels of triglyceride and cholesterol decreasing principally insulin and leptin. J Aging Res Clin Pract. 2014;3(1):31-35.

101. Hocaoglu AB, Karaman O, Erge DO, Erbil G, Yilmaz O, Kivcak B, Bagriyanik HA, Uzuner N. Effect of Hedera helix on lung histopathology in chronic asthma. Iran $\mathrm{J}$ Allergy Asthma Immunol. 2012;12(4):316-323. DOI: 011.04/ijaai.316323.

102. Liu BX, et al. Hederagenin from the leaves of ivy (Hedera helix L.) induces apoptosis in human LoVo colon cells through the mitochondrial pathway. BMC Complement and Altern Med. 2014;14(412):1-10. DOI: 10.1186/1472-6882-14-412.

103. Song J, et al. Antiviral activity of hederasaponin B from Hedera helix against enterovirus 71 subgenotypes C3 and C4a. Biomol Ther (Seoul.). 2014;22(1):41-46. DOI: 10.4062/biomolther.2013.108.

104. Hooshyar H, Talari S, Fevzi F. Therapeutic effect of Hedera helix alcoholic extract against cutaneous leishmaniasis caused by leishmania major in Balb/c mice. Jundishapur J Microb. 2014;7(4). DOI: 10.5812/jjm.9432. 